\title{
Reducing FASN expression sensitizes acute myeloid leukemia cells to differentiation therapy
}

\author{
Magali Humbert $\mathbb{1}^{1,2} \cdot$ Kristina Seiler $^{1,3} \cdot$ Severin Mosimann $^{1} \cdot$ Vreni Rentsch $^{1} \cdot$ Katyayani Sharma $^{3,4,5} \cdot$ \\ Amit V. Pandey $\mathbb{D}^{4,5}$. Sharon L. McKenna ${ }^{2,6}$. Mario P. Tschan $\mathbb{1}^{1,2,3}$
}

Received: 13 July 2020 / Revised: 14 February 2021 / Accepted: 1 March 2021 / Published online: 19 March 2021

(c) The Author(s) 2021. This article is published with open access

\begin{abstract}
Fatty acid synthase (FASN) is the only human lipogenic enzyme available for de novo fatty acid synthesis and is often highly expressed in cancer cells. We found that FASN mRNA levels were significantly higher in acute myeloid leukemia (AML) patients than in healthy granulocytes or $\mathrm{CD} 34^{+}$hematopoietic progenitors. Accordingly, FASN levels decreased during all-trans retinoic acid (ATRA)-mediated granulocytic differentiation of acute promyelocytic leukemia (APL) cells, partially via autophagic degradation. Furthermore, our data suggest that inhibition of FASN expression levels using RNAi or (-)-epigallocatechin-3-gallate (EGCG) accelerated the differentiation of APL cell lines and significantly re-sensitized ATRA refractory non-APL AML cells. FASN reduction promoted translocation of transcription factor EB (TFEB) to the nucleus, paralleled by activation of CLEAR network genes and lysosomal biogenesis. Together, our data demonstrate that inhibition of FASN expression in combination with ATRA treatment facilitates granulocytic differentiation of APL cells and may extend differentiation therapy to non-APL AML cells.
\end{abstract}

\section{Introduction}

While traditional chemotherapy and radiotherapy target highly proliferative cancer cells, differentiation-inducing

Edited by H. Ichijo

Supplementary information The online version contains supplementary material available at https://doi.org/10.1038/s41418021-00768-1.

Magali Humbert

magali.humbert@yahoo.fr

1 Institute of Pathology, Division of Experimental Pathology, University of Bern, Bern, Switzerland

2 TRANSAUTOPHAGY: European Network for Multidisciplinary Research and Translation of Autophagy Knowledge, COST Action, Bern, Switzerland

3 Graduate School for Cellular and Biomedical Sciences, University of Bern, Bern, Switzerland

4 Pediatric Endocrinology, Diabetology, and Metabolism, University Children's Hospital, Bern, Switzerland

5 Department of Biomedical Research, University of Bern, Bern, Switzerland

6 Cancer Research, UCC, Western Gateway Building, University College Cork, Cork, Ireland therapy aims to restore differentiation programs to drive cancer cells into maturation and ultimately into cell death. Differentiation therapies are associated with lower toxicity compared to classical cytotoxic therapies. The success of this therapeutic approach is exemplified by the introduction of all-trans retinoic acid (ATRA) in 1985 to treat acute promyelocytic leukemia (APL) [1]. The introduction of ATRA into the treatment regimen changed APL from being one of the most aggressive acute myeloid leukemia (AML) subtypes with a fatal course often within weeks only, to a curable disease with a complete remission rate of up to $95 \%$ when combined with anthracycline-based chemotherapy or arsenic trioxide [1]. APL is characterized by translocations involving the C-terminus of the retinoic acid receptor alpha (RARA) on chromosome 17 and genes encoding for aggregate prone proteins. Promyelocytic leukemia (PML)RARA is the most frequently expressed fusion protein. It is encoded by the translocation $\mathrm{t}(15 ; 17)$ and has a dominantnegative effect on RARA. RARA transcriptionally regulates multiple biological processes with a key role in differentiation [2]. Several reports suggest a beneficial effect of ATRA in combination therapies in non-APL AML cells [3-5]. Unfortunately, a variety of intrinsic resistance mechanisms in non-APL AML have been identified such as SCL overexpression, expression of PRAME and epigenetic 
silencing or mutation of RARA [6-9]. Deciphering the mechanisms active during ATRA-mediated differentiation at the molecular level will support the translation of differentiation therapy to non-APL AML patients. We and others have demonstrated the importance of autophagy in ATRA induced granulocytic differentiation of APL cells [10-15]. Autophagy is an intracellular degradation mechanism that ensures dynamic recycling of various cytoplasmic contents [16]. We thus aim to understand the role of autophagy in granulocytic differentiation and to define key druggable autophagy targets in this process.

Endogenous synthesis of fatty acids is catalyzed by fatty acid synthase (FASN), the only human lipogenic enzyme able to perform de novo synthesis of fatty acids [17, 18]. FASN is frequently overexpressed in a variety of tumor types including leukemias [19-25] while its expression in healthy adult tissues is low [26], with the exception of the cycling endometrium [27] and lactating breast [28]. Interestingly, FASN is upregulated in tumor-associated myeloid cells where it activates nuclear receptor peroxisome-proliferator-activated receptor beta/delta (PPAR $\beta / \delta$ ) [29], a key metabolic transcription factor in tumorigenesis $[30,31]$. Of note, activation of PPAR $\beta / \delta$ regulates anti-inflammatory phenotypes of myeloid cells in other biological contexts such as atherosclerosis and obesity [32-35]. We previously reported that (-)-epigallocatechin-3gallate (EGCG) improved ATRA-induced differentiation of APL cells by increasing the expression of death-associated protein kinase 2 (DAPK2). Furthermore, EGCG treatment reduces FASN expression levels in selected breast cancer cell lines [36]. The increased FASN expression in cancers including leukemias, its function in tumor-associated myeloid cells and its link to the differentiation enhancer DAPK2 prompted us to analyze the regulation and function of FASN during myeloid leukemic differentiation.

In the present study, we demonstrate that FASN expression is significantly higher in AML blasts partially due to low autophagic activity in those cells. We show that inhibiting FASN protein expression, but not its enzymatic activity, promotes differentiation of non-APL AML cells. Lastly, we link FASN expression to mTOR activation and inhibition of the key lysosomal biogenesis transcription factor TFEB.

\section{Material and methods}

\section{Primary cells, cell lines and culture conditions}

Fresh leukemic blast cells from untreated AML patients at diagnosis were obtained from the Inselspital Bern (Switzerland) were classified according to the FrenchAmerican-British classification and cytogenetic analysis. All leukemia samples had blast counts of $\sim 90 \%$ after separation of mononuclear cells using a Ficoll gradient
(Lymphoprep; Axon Lab AG, Switzerland), as described previously [37]. Protocols and use of 67 human samples acquired in Bern were approved by the Cantonal Ethical Committee at the Inselspital. The isolation of primary neutrophils (purity 95\%) was performed by separating blood cells from healthy donors using polymorphprep (Axon Lab AG, Switzerland). CD34 ${ }^{+}$cells from cord blood or bone marrow were isolated as previously described [37].

The human AML cell lines HT93, OCI/AML2, MOLM13 and NB4 were obtained from the Deutsche Sammlung von Mikroorganismen und Zellkulturen GmbH (DSMZ, Braunschweig, Germany). All cell lines were maintained in RPMI-1640 with $10 \%$ fetal calf serum, $50 \mathrm{U} / \mathrm{mL}$ penicillin and $50 \mu \mathrm{g} / \mathrm{mL}$ streptomycin in a $5 \% \mathrm{CO}_{2}-95 \%$ air humidified atmosphere at $37^{\circ} \mathrm{C}$. For differentiation experiments, AML cells were treated with $1 \mu$ M ATRA (ATRA; SigmaAldrich, Switzerland). Successful granulocyte differentiation was evidenced by CD11b surface expression measured by FACS.

293 T cells were maintained in DMEM (Sigma-Aldrich, St. Louis, MO, USA), supplemented with 5\% FBS, $1 \%$ penicillin/streptomycin, and $1 \%$ Hepes (Sigma-Aldrich, Switzerland), and kept in a $7.5 \% \mathrm{CO}_{2}-95 \%$ air humidified atmosphere at $37^{\circ} \mathrm{C}$.

\section{Antibodies}

Antibodies used were anti-FASN (3180; Cell Signaling, Switzerland), anti-LC3B (WB: NB600-1384, Novus biological, Switzerland; IF: 3868; Cell Signaling, Switzerland) anti-LAMP1 (14-1079-80; Thermofisher, Switzerland), anti-p62 (HPA003196; Sigma-Aldrich, Switzerland), antiTFEB (4240; Cell Signaling, Switzerland), anti-p-TFEB (Ser 211) (37681S, Cell Signaling, Switzerland), anti-pAKT (Ser473) (4060S, Cell Signaling, Switzerland) antiPTEN (9552, Cell Signaling, Switzerland), anti-ULK1 (4776; Cell Signaling, Switzerland), anti-p-ULK1 (Ser757, equivalent to Ser758 of human ULK1) (6888; Cell Signaling, Switzerland), anti-ATG13 (6940; Cell Signaling, Switzerland), anti-pATG13 (Ser318) (600-401-C49; Rockland, Switzerland), anti p-mTOR (Ser2448) (5536; Cell Signaling, Switzerland), p4E-BP1 (Thr37/46) (2855; Cell Signaling, Switzerland), anti- $\alpha$-tubulin (3873; Cell Signaling, Switzerland), anti-cleaved PARP (9541; Cell Signaling, Switzerland), anti yH2AX (2577; Cell Signaling, Switzerland) and anti-CD11b-PE (R0841; Dako, Switzerland).

\section{Cell lysate preparation and western blotting}

Whole-cell extracts were prepared using UREA lysis buffer and $30-60 \mu \mathrm{g}$ of total protein was loaded on a $7.5 \%$ or $12 \%$ 
denaturing polyacrylamide self-cast gels (Bio-Rad, Switzerland). Blots were incubated with the primary antibodies in TBS $0.05 \%$ Tween-20/5\% milk overnight at $4{ }^{\circ} \mathrm{C}$ and subsequently incubated with HRP coupled secondary goat anti-rabbit (7074; Cell Signaling, Switzerland) and goat anti-mouse antibody (7076; Cell Signaling, Switzerland) at $1: 5-10,000$ for $1 \mathrm{~h}$ at room temperature. Blots were imaged using Chemidoc (Bio-Rad, Switzerland) and ImageLab software.

\section{Lentiviral vectors}

pLKO.1-puro lentiviral vectors expressing shRNAs targeting FASN (shFASN_1: NM_004104.x-1753s1c1 and shFASN_2: NM_004104.x-3120s1c1) were purchased from SigmaAldrich. A mCherry-LC3B lentiviral vector was kindly provided by Dr. Maria S. Soengas (CNIO, Molecular Pathology Program, Madrid, Spain). All vectors contain a puromycin antibiotic resistance gene for the selection of transduced mammalian cells. Lentivirus production and transduction were performed as previously described [37, 38]. Transduced NB4, MOLM-13 and OCI/AML2 cell populations were selected with $1.5 \mu \mathrm{g} / \mathrm{ml}$ puromycin for 4 days and knockdown efficiency was assessed by western blot analysis.

\section{Immunofluorescence microscopy}

Cells were prepared as previously described [14]. Briefly, cells were fixed and permeabilized with ice-cold $100 \%$ methanol for $4 \mathrm{~min}$ (FASN, mTOR, LC3B and LAMP1 staining) or $2 \%$ paraformaldehyde for $7 \mathrm{~min}$ followed by $5 \mathrm{~min}$ in PBS $0.1 \%$ TRITON X-100 (TFEB and tubulin staining) and then washed with PBS. Cells were incubated with primary antibody for $1 \mathrm{~h}$ at room temperature followed by washing steps with PBS containing $0.1 \%$ Tween (PBS-T). Cells were incubated with the secondary antibody (anti-rabbit, 111-605-003 (Alexa Fluor 647) 111-096-045 (FITC); anti-mouse, (Cy3) 115-605-003 (Alexa Fluor ${ }^{\circledR}$ 647); Jackson ImmunoResearch, West Grove, PA, USA) for $1 \mathrm{~h}$ at room temperature. Prior to mounting in fluorescence mounting medium (S3032; Dako, Switzerland) cells were washed three times with PBS-Tween. Images were acquired on an Olympus FluoView-1000 confocal microscope (Olympus, Volketswil, Switzerland) at $\times 63$ magnification.

\section{Acridine Orange staining}

Cells were washed three times with PBS and resuspended in RPMI $10 \%$ FBS containing $5 \mathrm{ug} / \mathrm{mL}$ Acridine Orange (A3568, Invitrogen, Switzerland) to a concentration of $0.2 \times 106$ cells per ml. Cells were then incubated at $37{ }^{\circ} \mathrm{C}$ for $20 \mathrm{~min}$ and washed three times with PBS. Acridine Orange staining was measured by FACS analysis using a
$488 \mathrm{~nm}$ laser with 530/30 (GREEN) and 695/40 (RED) filters on a FACS LSR-II (BD Biosciences, Switzerland). Data were analyzed with FlowJo software (Ashland, OR, USA). The software derived the RED/GREEN ratio and we compared the distribution of populations using the Overton cumulative histogram subtraction algorithm to provide the percentage of cells more positive than the control.

\section{Nitroblue tetrazolium reduction test}

Suspension cells $(5 \times 105)$ were resuspended in a $0.2 \%$ nitro blue tetrazolium (NBT) solution containing $40 \mathrm{ng} / \mathrm{ml}$ PMA and incubated $15 \mathrm{~min}$ at $37^{\circ} \mathrm{C}$. Cells were then washed with PBS and subjected to cytospin. Counterstaining was done with $0.5 \%$ Safranin O for 5 min (HT90432; Sigma-Aldrich, Switzerland). The NBT-positive and negative cells were scored under a light microscope (EVOS XL Core, Thermofisher, Switzerland).

\section{Trypan blue exclusion counting}

Trypan blue exclusion cell counting was performed to assess cellular growth. $20 \mu \mathrm{L}$ of cell suspension was incubated with an equal volume of $0.4 \%$ (w/v) trypan blue solution (Sigma-Aldrich, Switzerland). Cells were counted using a dual-chamber hemocytometer and a light microscope (EVOS XL Core, Thermofisher, Switzerland).

\section{Real-time quantitative RT-PCR (qPCR)}

Total RNA was extracted using the RNeasy Mini Kit and the RNase-Free DNase Set according to the manufacturer's protocol (Sigma-Aldrich, Switzerland). Total RNA was reverse transcribed using all-in-one RT-PCR (BioTool, Switzerland). Taqman ${ }^{\circ}$ Gene Expression Assays for FASN, ELOVL6, SCD1, ACACA, BECN1, GABARAP, STK4, and WDR45 were Hs01005632_g1, Hs00907564_m1, Hs01682761_m1, Hs01046047_m1, Hs00186838_m1, Hs00925899_g1, Hs00178979_m1 and Hs01079049_g1, respectively. Specific primers and probes for $H M B S$ have been already described [37]. Data represent the mean \pm s.d. of at least two independent experiments.

\section{TaqMan low-density array (LDA)}

Total RNA was extracted using the Qiagen RNeasy kit and the RNase-Free DNase Set to minimize the risk of contamination with genomic DNA, according to the manufacturer's protocol (Qiagen AG). 1-2 $\mu \mathrm{g}$ of total RNA was reverse transcribed using pd(N)6 random primers (Roche Diagnostics AG, Rotkreuz, Switzerland). Real-time RT-PCR for LDAs was performed using the ABI 7900HT Fast Real-Time PCR 
System (Applied Biosystems, Rotkreuz, Switzerland) and 400 ng of cDNA. Taqman Gene Expression Assays for HMBS, ABL1, and FASN preloaded on LDAs or used in a 96-well format using the ABI PRISM 7700 Sequence Detection System were Hs00609297_m1, Hs00245445_m1, and Hs01005632_g1 respectively (Applied Biosystems).

Measured cycle threshold $(\mathrm{Ct})$ values represent $\log 2$ expression levels. Values were normalized to the expression levels of two housekeeping genes $H M B S$ and $A B L 1$ as described in [39].

\section{Lipid extraction}

The protocol was performed as previously described [40]. Briefly, NB4 cells $(0.5 \times 105$ cells $/ \mathrm{ml})$ were labelled with $0.5 \mu \mathrm{Ci} / \mathrm{ml}\left[{ }^{14} \mathrm{C}\right]$-Acetic Acid [American Radiolabeled Chemical Inc., St. Louis, MO, USA] for $6 \mathrm{~h}$ in the presence or absence of different concentrations of $\mathrm{C} 75$ and Orlistat. Cells were harvested using $0.5 \mathrm{ml}$ PBS and lipids were extracted using chloroform/methanol (3:1, v/v). The chloroform phase was evaporated under nitrogen and concentrated lipids were dissolved in $30 \mu$ dichloromethane. Lipids were separated by thin layer chromatography over silicagel (SIL G/UV254) TLC plates (Macherey-Nagel, Oensingen, Switzerland) using hexane/diethyl ether/acetic acid (70:30:1, v/v) as mobile phase. Palmitic acid (PA) spots were identified using a standard [Sigma-Aldrich, Basel, Switzerland] solution by exposing the TLC to Iodine vapor. The corresponding radiolabeled spots were visualized by autoradiography using a Fuji FLA-7000 PhosphoImager (Fujifilm, Dielsdorf, Switzerland) and quantified using ImageQuant software. The amount of PA formed in the presence of drugs was calculated as a percent of radioactivity incorporated into the control samples.

\section{Statistical analysis}

Nonparametric Mann-Whitney-U tests were applied to compare the difference between two groups and Spearman Coefficient Correlation using Prism software (GraphPad Software, Inc., Jolla, CA, USA). $P$ values $<0.05$ were considered statistically significant. The error bar on graphs represents the SD of at least two biological replicates performed in two technical replicates.

\section{Results}

\section{Primary AML blast cells express significantly higher FASN levels compared to mature granulocytes}

Cancer cells frequently express high levels of FASN compared to their healthy counterparts [19-25]. We examined
FASN mRNA expression in an AML patient cohort. FASN mRNA levels in AML samples $(n=68)$ were compared to the levels in granulocytes $(n=5)$ and $\mathrm{CD} 34^{+}$human hematopoietic progenitor cells $(n=3)$ from healthy donors. We found that $F A S N$ expression was significantly higher in AML patients compared to healthy granulocytes $(p<0.05)$ (Fig. 1A). We obtained similar findings by analyzing FASN expression in AML patient data available from the Blood spot gene expression profile data base [41] (Fig. 1B). In addition, hematopoietic stem cells from healthy donors express significantly lower FASN mRNA transcript levels than AML blasts (Fig. 1B). Next, we asked if FASN expression was altered during granulocytic differentiation of APL cells. We analyzed FASN protein expression following ATRA-induced differentiation of two APL cell lines, NB4 and HT93. Successful differentiation was confirmed by flow cytometry, using CD11b surface marker expression (Supplementary Fig. 1A-C). ATRA treatment resulted in markedly reduced FASN protein levels from day two onwards (Fig. 1C) whereas FASN mRNA levels did not decrease (Fig. 1D). Interestingly, other transcriptional targets of the sterol regulatory element binding protein 1 (SREBP1), such as ELOVL6, SCD1 and ACACA, were upregulated, yet FASN (also a transcriptional target), was not (Supplementary Fig. 1C). Collectively this data suggests that high FASN expression is linked to an immature blastlike phenotype and that the decrease in FASN protein levels during ATRA-induced differentiation is mediated at the protein level, rather than by transcriptional mechanisms.

\section{FASN protein is degraded via macroautophagy during ATRA-induced granulocytic differentiation}

We and others have demonstrated that autophagy gene expression is repressed in AML samples compared to granulocytes from healthy donors and that autophagy activity is essential for successful ATRA-induced APL differentiation [10-15, 42]. The marked decrease in FASN protein upon ATRA-induced differentiation is likely to be due to post-transcriptional regulation as transcript levels are unchanged and the protein has a long half-life (1-3 days) [26, 43]. Moreover, FASN has been detected inside autophagosomes, for instance in yeast and in the breast cancer cell line MCF7 [44, 45]. Therefore, we hypothesized that ATRA-induced autophagy participates in the degradation of FASN during differentiation of APL cells. To examine whether autophagy is involved in FASN degradation, we treated NB4 cells for $24 \mathrm{~h}$ with different concentrations of Bafilomycin A1 (BafA1), a specific inhibitor of vacuolar-type $\mathrm{H}^{+}$-ATPase [46, 47], alone or in combination with ATRA. FASN protein was found to accumulate in the presence of BafA1 at day 1 and 2 of ATRA treatment in NB4 cells, together with autophagy markers p62 and 
A

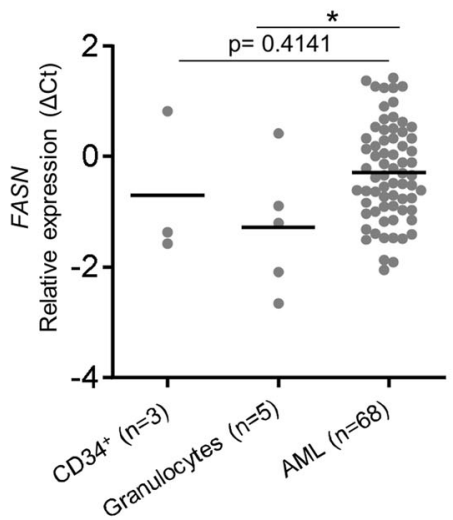

B

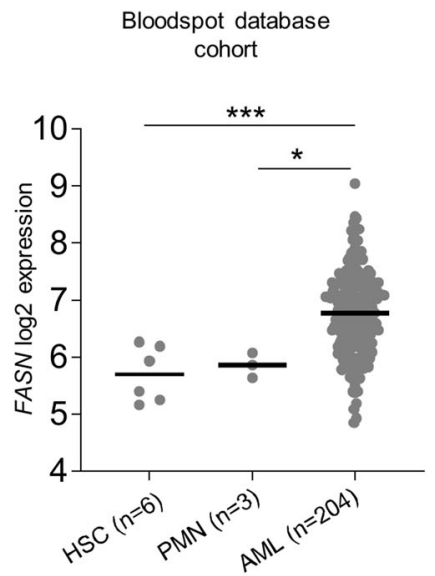

Fig. 1 Increased FASN expression is associated with an immature AML blast phenotype. A FASN mRNA levels in AML blasts, CD34 ${ }^{+}$ progenitor cells and granulocytes from healthy donors were quantified by qPCR. All the samples were obtained from the Inselspital, Bern, Switzerland. AML patient cells and granulocytes were isolated using Ficoll gradient density centrifugation. Values are the differences in Ctvalues between FASN and the housekeeping genes HMBS and ABL1. MNW $* p<0.05, * * p<0.0$. B Blood spot data bank analysis of FASN expression in AML blasts compared to granulocytes from healthy donors. MNW $* p<0.05,{ }^{* *} p<0.01$. C Western blot analysis of FASN

LC3B-II (Fig. 2A-B). To validate these findings, we utilized NB4 cells stably expressing mCherry-LC3B. Cells were treated with different concentrations of BafAl with or without ATRA for $24 \mathrm{~h}$ and FASN, as well as LC3B localization, was assessed. Endogenous FASN (cyan) showed colocalization with mCherry-LC3B (red) in BafA1 and ATRA treated cells (Fig. 2C). In addition, we found colocalization with endogenous FASN (red) and p62 (green) in NB4 parental cells treated with both ATRA and BafA1 for $24 \mathrm{~h}$ (Fig. 2D). It is possible that p62 may help to sequester FASN to the autophagosome. These data suggest that FASN is a target for autophagic degradation during granulocytic differentiation of APL cells.
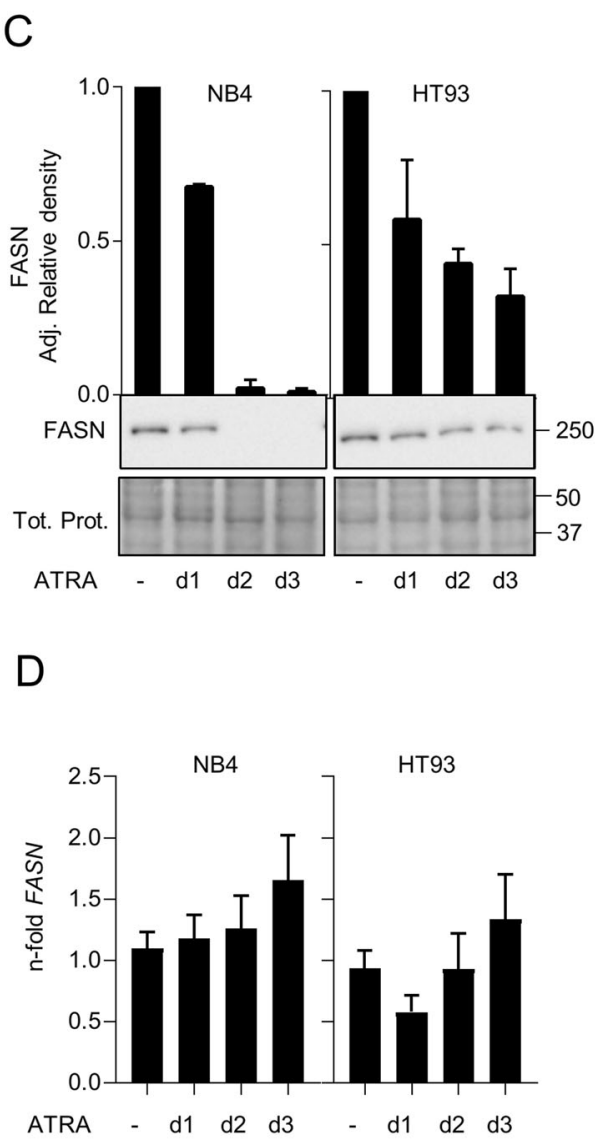

regulation in NB4 and HT93 APL cells upon ATRA treatment at different time points (1,2 and 3 days). Total protein was extracted and submitted to immunoblotting using anti-FASN antibody. Total protein is shown as loading control. The relative protein expressions were normalized to total protein and quantified using ImageJ software $(\mathrm{NIH}$, Bethesda, MD, USA). Data are represented as a mean $(n=3)$, Error bars: SD. D Evaluation of FASN transcript levels upon ATRA treatment was done by qPCR. Values were normalized to the HMBS housekeeping gene. Results of at least three independent experiments are shown as n-fold regulation compared with non-treated cells.

We have previously shown that EGCG improves the response to ATRA in AML cells by inducing DAPK2 expression, a key kinase in granulocytic differentiation [48]. Furthermore, EGCG was reported to decrease FASN expression [36] and this was reproducible in our APL cell line model (Supplementary Fig. 2A-B). Using different EGCG doses and treatment time points, we confirmed that EGCG improves ATRA-induced differentiation in NB4 cells, as evidenced by increased NBT positive cells and CD11b surface expression (Supplementary Fig. 2C-E). Importantly, increased differentiation when combining ATRA with EGCG was paralleled by enhanced autophagic activity (Supplementary Fig. 2F-G). Autophagy induction 
A

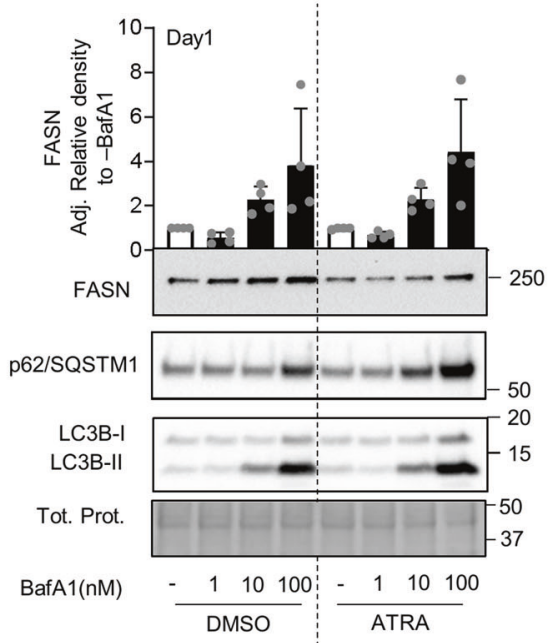

C
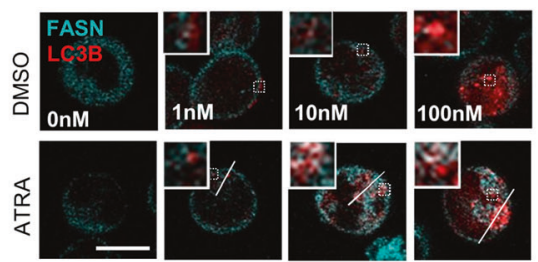

ATRA Intensity plot - FASN
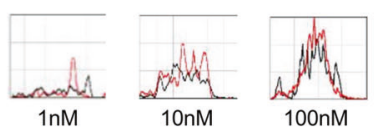

E

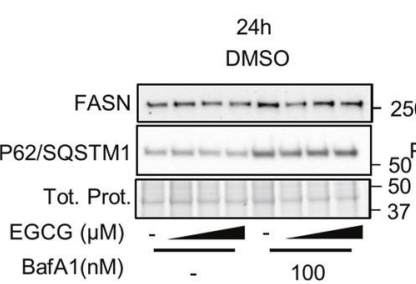

$\mathrm{F}$
B
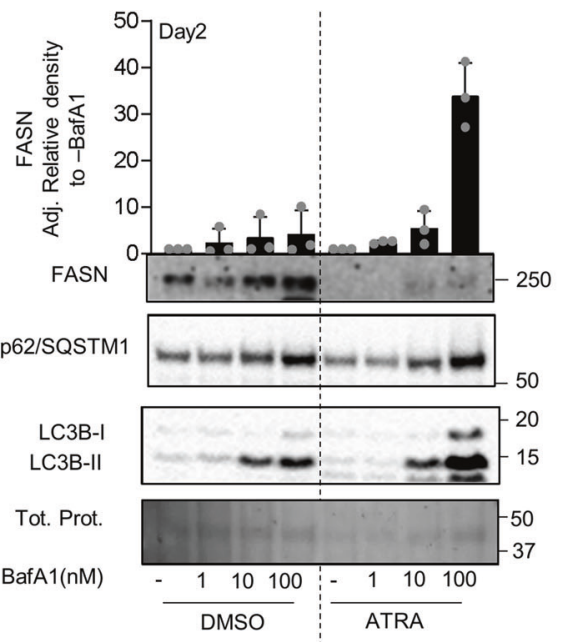

D
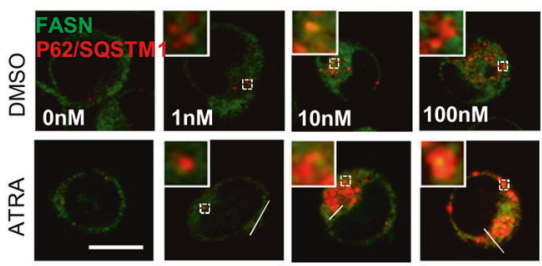

ATRA

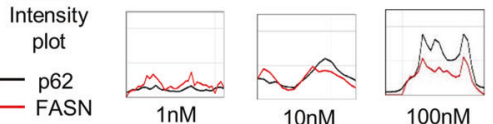

- FASN

DMSO

G

48h
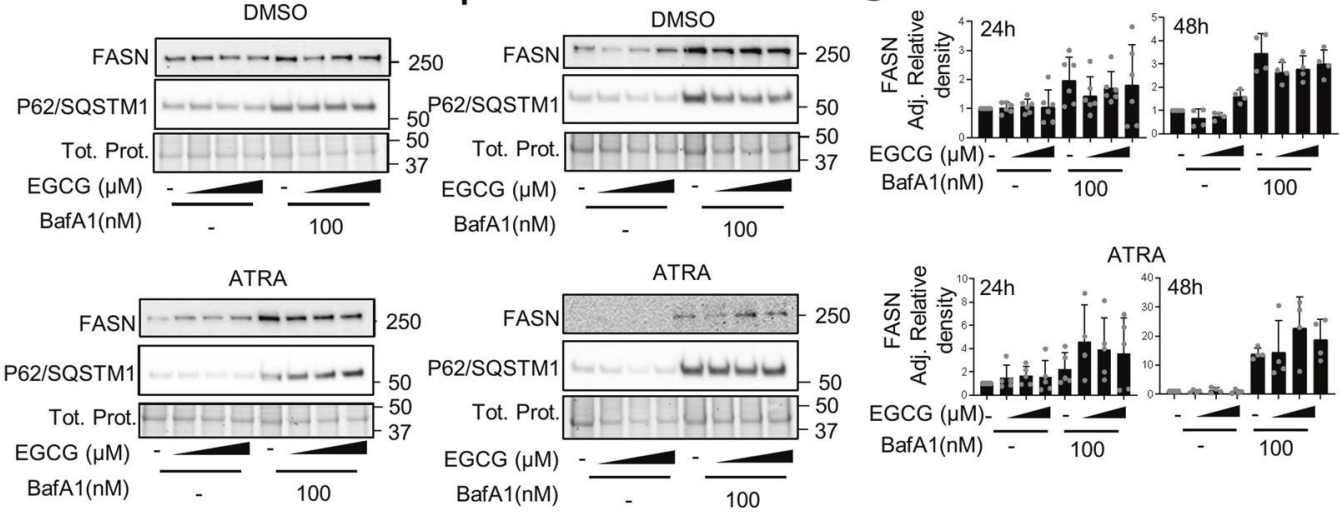

Fig. 2 FASN is degraded via autophagy. A-B NB4 cells were treated with ATRA and three concentrations of Bafilomycin A1 (BafA1) for $24 \mathrm{~h} \mathrm{(A)} \mathrm{and} 48 \mathrm{~h}$ (B). NB4 cells were lysed and subjected to western blot analysis as described in 1C. Quantification of the bands was done using ImageJ software and normalized to control-treated cells. Data are represented as a mean of at least three biological replicates, Error bars: SD. C NB4 cells stably expressing mCherryLC3B were treated with ATRA and different concentrations of Bafilomycin A1 (BafA1) for $24 \mathrm{~h}$. NB4 mCherry-LC3B cells were fixed and stained for endogenous FASN. The colocalization analysis was

was determined by quantifying endogenous, lipidated LC3B-II by western blotting and a dual-tagged mCherryGFP-LC3B expression construct as described previously $[13,49,50]$. Autophagic flux quantification upon EGCG performed using ImageJ software. Scale: $10 \mu \mathrm{m}$ D NB4 cells were treated as in $2 \mathrm{C}$ and fixed and stained for endogenous FASN and p62. The colocalization analysis was performed using ImageJ software. Scale: $10 \mu \mathrm{m}$. Results shown are from at least two biological duplicates. E-G EGCG potentiate ATRA-induced FASN degradation by autophagy. E-F FASN and p62 western blot analysis of NB4 cells treated with DMSO (right panel) or ATRA (left panel), in combination with different EGCG $(5-15 \mu \mathrm{M})$ and BafA1 $(100 \mathrm{~nm})$ concentrations for $24 \mathrm{~h}(\mathbf{E})$ or $48 \mathrm{~h}(\mathbf{F})$. Total cell lysates were subjected to western blotting. G Quantification of the western blot was done as in Fig. 1C.

treatment was performed in the presence or absence of BafA1 [50]. We found no significant changes in cell death or proliferation measured by DAPI staining and trypan blue exclusion, respectively (Supplementary Fig. 2H-I). 
Co-treating NB4 parental cells with EGCG and ATRA as well as blocking autophagy using BafA1, resulted in a higher accumulation of FASN protein at $24 \mathrm{~h}$ or $48 \mathrm{~h}$ (Fig. 2E-G). Together, our data demonstrate that FASN can be degraded via autophagy during APL cell differentiation and that co-treatment with EGCG further promotes FASN protein degradation.

\section{Inhibiting FASN protein expression but not its catalytic function accelerates ATRA-induced granulocytic differentiation in APL cell lines}

Next, we evaluated the impact of modulating FASN expression and activity on myeloid differentiation. Therefore, we genetically inhibited FASN expression using lentiviral vectors expressing two independent shRNAs targeting FASN in the NB4 APL cell line model. Knockdown efficiency was validated by western blotting (Fig. 3A). We found that ATRA treatment significantly reduced the doubling time (Supplementary Fig. 3A-B) and lowered the accumulation of DNA damage as indicated by yH2AX immunofluorescence staining in NB4 FASN depleted cells (Supplementary Fig. 3C-D). Of note, at steady-state conditions, knocking down FASN did not affect proliferation compared to control cells. Knocking down FASN in NB4 cells resulted in accelerated differentiation into functional granulocytes compared to the control cells as shown by NBT assays (Fig. 3B-C) and by CD11b surface expression analysis (Fig. 3D). We then assessed the effects of two pharmacological FASN inhibitors, C75 and Orlistat. We used $\mathrm{C} 75$ and Orlistat concentrations that do not induce significant cell death (Supplementary Fig. 4A-B) or decrease proliferation (Supplementary Fig. 4C-D) to avoid non-specific effects. Of note, FASN protein levels in APL cells were not reduced by C75 or Orlistat treatment (Supplementary Fig. 4E-F) while inhibiting its activity (Supplementary Fig. 4G-H). Unexpectedly, co-treatment of NB4 cells with ATRA and C75 (Fig. 3E-G) or Orlistat (Fig. 3HJ) did not reproduce the phenotype of the FASN knockdown cells. Indeed, cells were differentiating similarly or less compared to control-treated cells as demonstrated by NBT assays (Fig. 3E-F and Fig. 3H-I) and CD11b surface expression (Fig. 3G and Fig. 3J). Therefore, we conclude that the catalytic activity of FASN is not involved in impeding ATRA-mediated differentiation in NB4 cells.

\section{FASN attenuates autophagy by increasing mTOR activity}

FASN has been previously reported to promote carcinogenesis by activating mTOR, a master negative regulator of autophagy, via AKT signaling in hepatocellular carcinoma $[51,52]$. ATRA treatment in APL reduces mTOR activity leading to autophagy activation [10]. We, therefore, hypothesized that FASN may negatively regulate autophagy via mTOR in APL cells, thereby impeding ATRA-induced differentiation. Therefore, we initially confirmed that FASN expression impacts autophagic activity in our system. Autophagy induction was established by quantifying endogenous LC3B dots formation by immunofluorescence microscopy (IF) after ATRA treatment [50]. In order to measure autophagic flux, ATRA treatment was performed in the presence or absence of BafA1 (Fig. 4A-B) [50]. In addition, we looked at the direct consequences of mTOR activity on ULK1 and ATG13 phosphorylation. ULK1 (ATG1), a key autophagy gene of the initiation complex, is inhibited by mTOR-mediated phosphorylation at Ser757, leading to reduced autophagic activity (Fig. 4C) [53]. In line with FASN activating mTOR, lowering FASN expression by shRNA (Fig. 4D) resulted in decreased mTOR phosphorylation at Ser2448 (Fig. 4E) and mTOR-mediated downstream phosphorylation of ULK1 at Ser758 (Fig. 4F). Elevated ULK1 activity was confirmed by an increase of ATG13 activating phosphorylation at Ser318 (Fig. 4G) $[54,55]$.

We then asked how FASN regulates mTOR activity. First, we tested whether FASN is localized to the lysosome by immunofluorescence microscopy upon ATRA treatment in NB4 cells. Interestingly, FASN localized to LAMP1 ${ }^{+}$ vesicles during steady-state conditions. Furthermore, ATRA treatment reduced both protein and FASN localization to $\mathrm{LAMP}^{+}$vesicles (Fig. 5A). In addition, lowering FASN expression led to a reduced lysosomal localization of mTOR (Fig. 5B). Next, we asked whether the mTOR upstream regulators AKT and PTEN were influenced by FASN expression. We treated FASN depleted NB4 cells for 3 days with ATRA and quantified AKT protein phosphorylation and PTEN protein levels. Furthermore, we analyzed two additional mTOR downstream targets namely p-4EBP1 (Thr37/46) and p-TFEB (Ser211). Interestingly, we found a compensatory activation of AKT in NB4 FASN knockdown cells while no marked differences in PTEN and p-4EBP1 levels were seen. Of note, TFEB was less phosphorylated in FASN depleted than in SHC002 control NB4 cells (Fig. 5C-D).

These results suggest that FASN expression promotes mTOR activity at the lysosomes, which in turn enhances autophagy inhibition in AML cells.

\section{FASN expression negatively affects transcription factor EB (TFEB) activation}

mTOR phosphorylates the transcription factor EB (TFEB), a master regulator of lysosome biogenesis, leading to the sequestration of TFEB within the cytoplasm and inhibition of its transcriptional activity [56-59]. TFEB is a key 

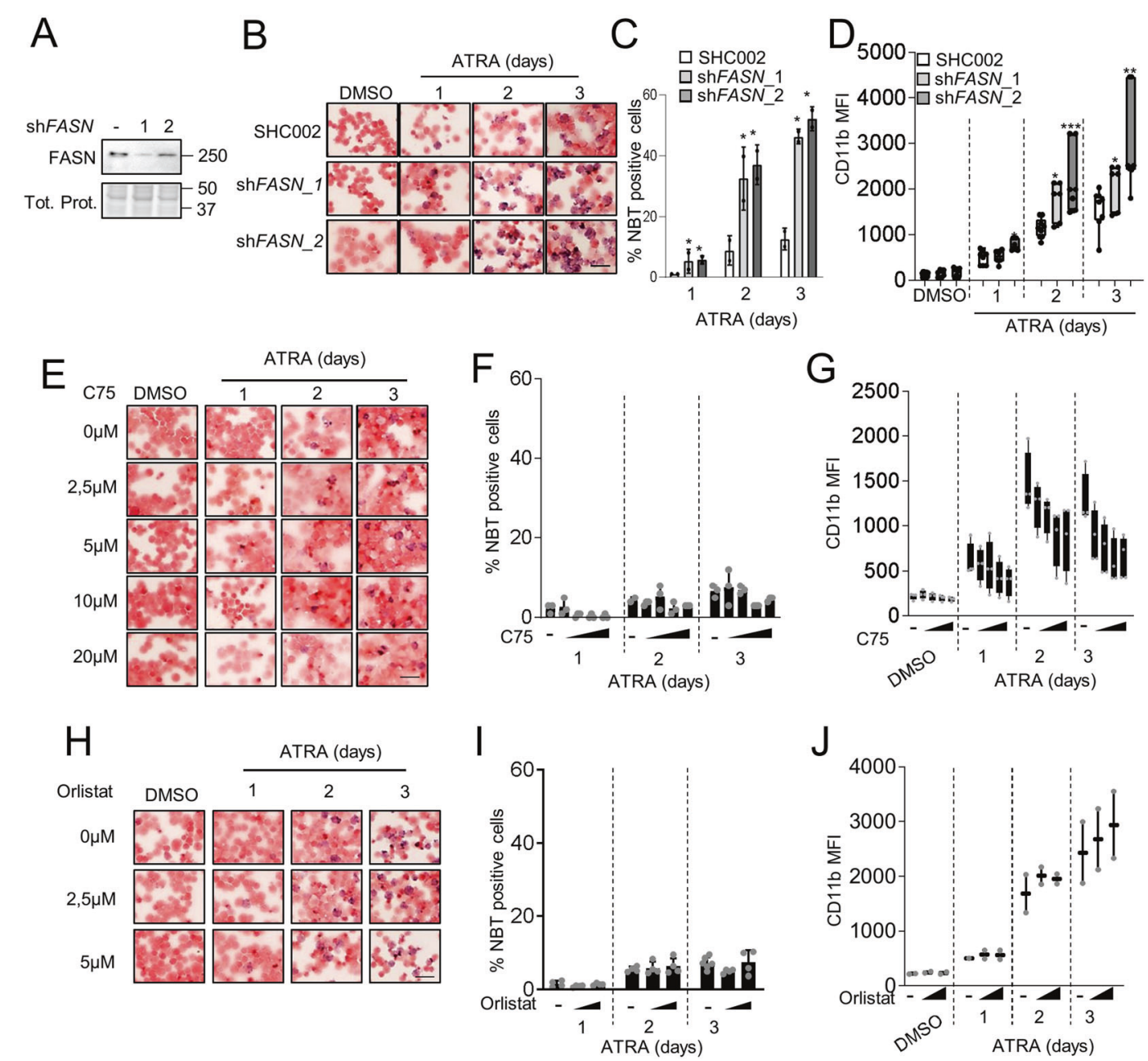

Fig. 3 Reducing FASN protein levels improves ATRA-mediated neutrophil differentiation of APL cells. A-D NB4 cells were stably transduced with non-targeting shRNA (SHC002) or shRNAs targeting FASN (shFASN_1 and shFASN_2) lentiviral vectors and differentiated with $1 \mu \mathrm{M}$ ATRA for 1,2 or 3 days. A FASN western blot analysis of control and $\operatorname{sh} F A S N\left(\operatorname{sh} F A S N \_1, \_2\right)$ expressing NB4 cell populations. B-C NBT reduction in ATRA-treated NB4 control (SHC002) and FASN knockdown (shFASN_1,_2) cells. B Representative images of NBT assays in control and FASN depleted NB4 cells. Scale $20 \mu \mathrm{M}$. C Quantification of the percentage of $\mathrm{NBT}^{+}$cells. D Flow cytometry analysis of CD11b surface expression NB4 control (SHC002) and FASN knockdown ( $\left.\operatorname{sh} F A S N \_1, \ldots 2\right) \mathrm{NB} 4$ cells upon ATRA treatment. E-G NB4 cells were treated with the indicated C75 concentrations for 3 days in combination with ATRA. E-F NBT reduction during ATRA-mediated neutrophil differentiation of NB4 control and C75

transcriptional regulator of more than 500 genes that comprise the CLEAR (Coordinated Lysosomal Expression and Regulation) network of autophagy and lysosomal genes (Supplementary Fig. 5A). A recent study demonstrated a key role of TFEB during ATRA-induced differentiation [15]. We, therefore, investigated the relationship between FASN and CLEAR network gene expression. Interestingly, several TFEB downstream targets from the different categories (lysosomal hydrolases and accessory proteins, treated cells. E Representative images of NBT assays in control and C75 treated NB4 cells upon ATRA-mediated differentiation. Scale 20 $\mu \mathrm{M}$. F Quantification of the percentage of $\mathrm{NBT}^{+}$cells. G Flow cytometry analysis of CD11b surface expression in NB4 control and C75 treated cells upon ATRA-mediated differentiation. H-J NB4 cells were treated with the indicated Orlistat concentrations for 3 days in combination with ATRA. H-I NBT reduction during ATRA-mediated neutrophil differentiation of NB4 control and Orlistat treated cells. H Representative images of NBT assays in control and Orlistat treated NB4 cells upon ATRA-mediated differentiation. Scale $20 \mu \mathrm{M}$ I Quantification of the percentage of $\mathrm{NBT}^{+}$cells. J Flow cytometry analysis of CD11b surface expression in NB4 control and Orlistat treated cells upon ATRA-mediated differentiation. Data are represented as a mean $(n=3)$, Error bars: SD.

lysosomal membrane, lysosomal acidification, nonlysosomal proteins involved in lysosomal biogenesis and autophagy) are negatively associated with FASN transcript levels in two primary AML patient cohorts from TCGA analyzed using the UCSC Xena platform [60] and the Blood spot gene expression profiles data base [41] (Fig. 6A, Supplementary Fig. 5B-C Supplementary Table 1-2). Furthermore, analyzing RNA-seq data of NB4 cells treated with ATRA confirmed a reduction of FASN expression 
A

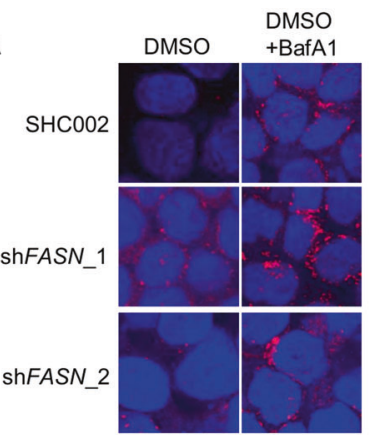

C

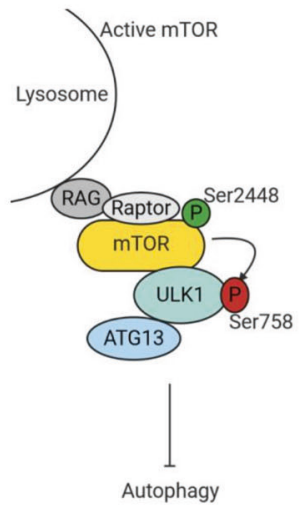

E

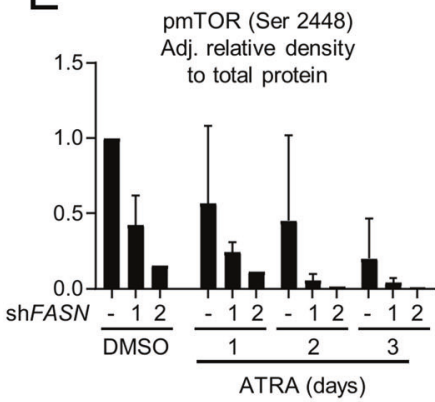

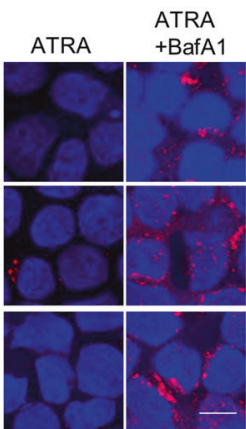

Inactive mTOR

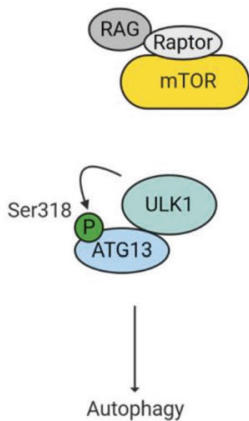

$\mathrm{F}$

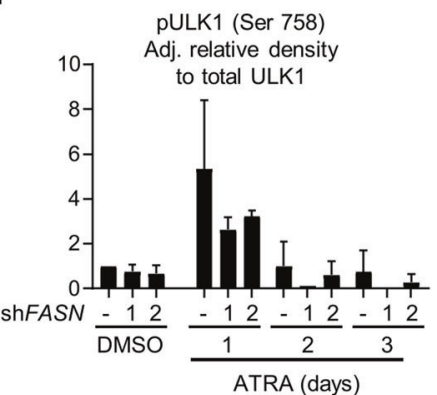

$\mathrm{D}$ $\square \mathrm{SHCOO2}$
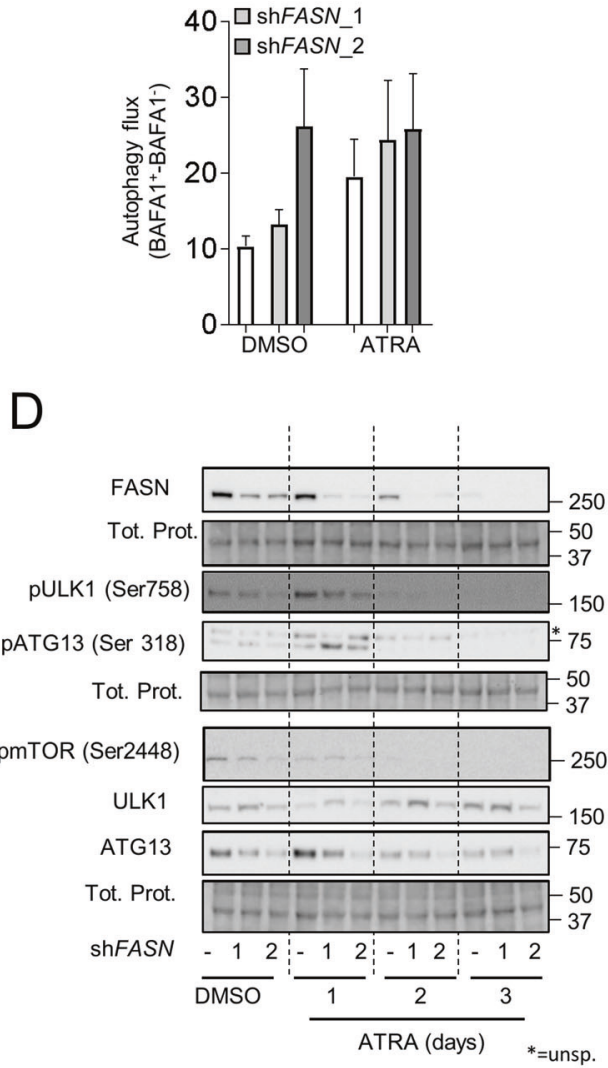

G

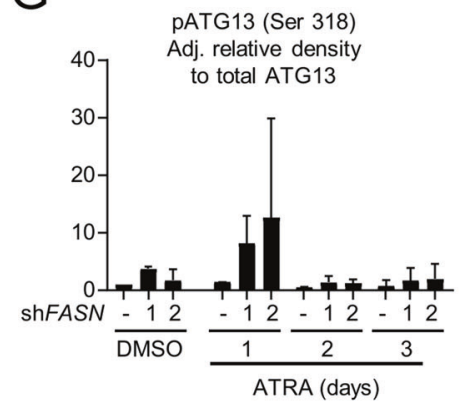

Fig. 4 FASN expression is linked to increased mTOR activity. A-C Autophagy induction in NB4 shFASN cells treated with $1 \mu \mathrm{M}$ ATRA for $24 \mathrm{~h}$, in the presence or absence of BafA1 during the last $2 \mathrm{~h}$ before harvesting. A-B NB4 control (SHC002) and FASN knockdown (shFASN_1, _2) cells were subjected to LC3B immunofluorescence. A Representative picture of LC3B punctae in NB4 control (SHC002) and FASN knockdown (shFASN_1, _2) cells. Scale: $10 \mu \mathrm{m}$. B Quantification of autophagy flux. Three independent experiments were quantified as described in [13]. C Scheme of mTOR activity on the ULK1 complex. D NB4 control (SHC002) and FASN knockdown

paralleled by increased TFEB and TFEB target gene transcript levels [15] (Fig. 6B). To test if the FASN-mTOR pathway is involved in regulating TFEB activity, we analyzed the cellular localization of TFEB upon ATRA treatment in NB4 control and FASN depleted cells. First, we $\left(\operatorname{sh} F A S N \_1, \_2\right)$ cells were treated for 1-3 days with ATRA. Total protein was extracted and subjected to immunoblotting using antiFASN, anti-pmTOR(Ser2448), anti- pULK1(Ser757), anti-ULK1, anti-pATG13(Ser318) and anti-ATG13 antibodies. E-F Relative protein expressions of two independent experiments were normalized to total protein or the respective non-phosphorylated protein and quantified using ImageJ software (NIH, Bethesda, MD, USA). E pmTOR(Ser2448) normalized to total protein. F pULK1(Ser758) normalized to total ULK1. G pATG13(Ser318) normalized to total ATG13. Results shown are from at least two biological duplicates.

investigated if TFEB translocates to the nucleus following ATRA treatment and if this translocation is paralleled by an increase in lysosome numbers (LAMP1 ${ }^{+}$dots), assessed by immunofluorescence microscopy (Supplementary Fig. 6AB). Indeed, ATRA treatment resulted in increased LAMP1 ${ }^{+}$ 

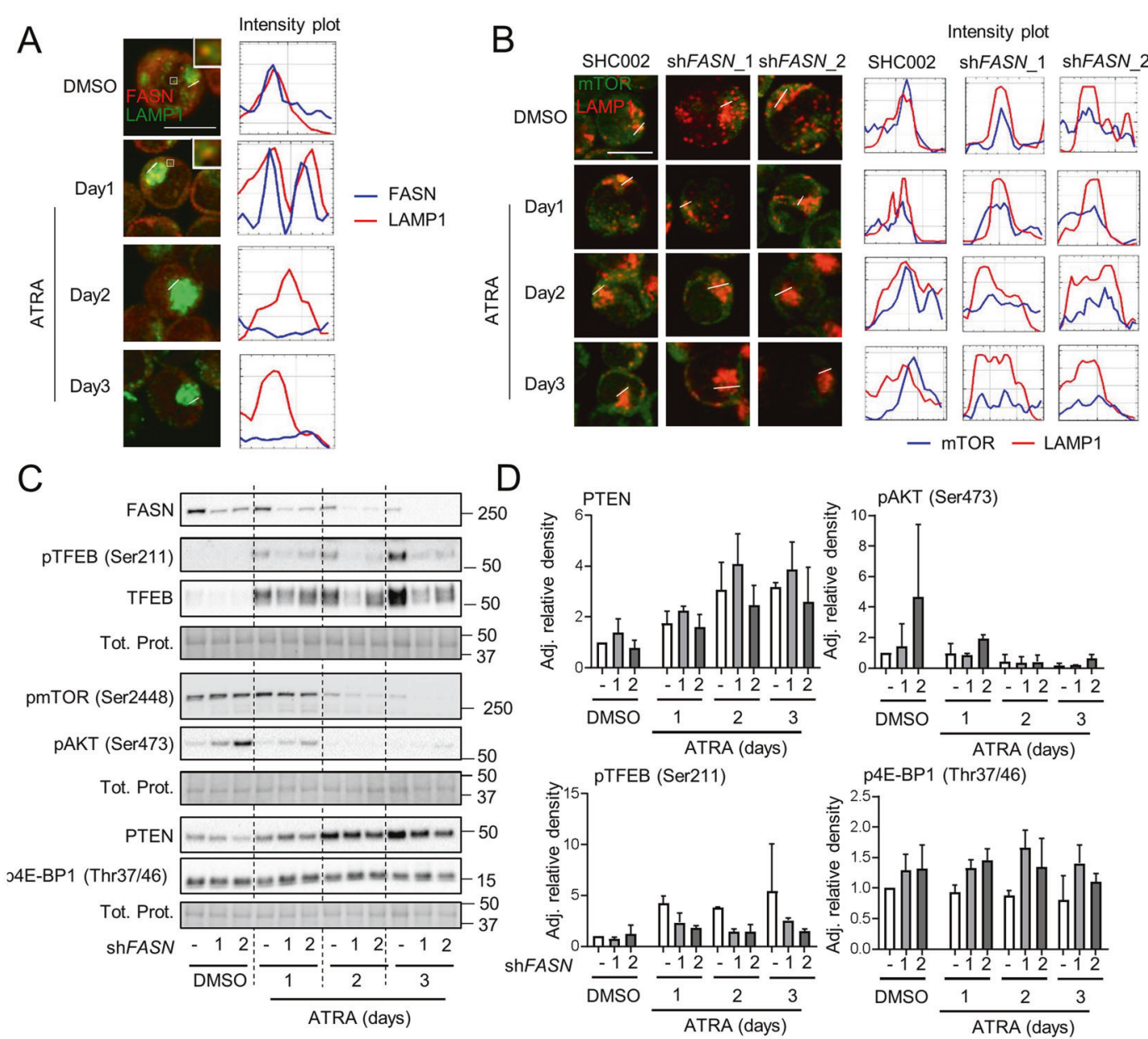

Fig. 5 FASN localizes at the lysosome to increase mTOR activity. A NB4 cells were treated as in 2D and fixed and stained for endogenous FASN (red) and LAMP1 (green) protein. The colocalization analysis was performed using ImageJ software. Scale: $10 \mu \mathrm{m}$. Results shown are from at least two biological duplicates. B-D NB4 control (SHC002) and FASN knockdown $\left(\operatorname{sh} F A S N \_1,22\right)$ cells were treated for 1-3 days with ATRA. B Immunofluorescence microscopy of endogenous mTOR (green) and LAMP1 (red). The colocalization analysis was performed using ImageJ software. Scale: $10 \mu \mathrm{m}$. C Total protein was extracted and subjected to immunoblotting using antiFASN, anti-pmTOR(Ser2448), anti-pTFEB(Ser211), anti-TFEB, antipAKT(Ser473) anti-PTEN and anti-p4E-BP1 (Thr37/46) antibodies. D Relative protein expressions of two independent experiments were normalized to total protein or the respective non-phosphorylated protein and quantified using ImageJ software (NIH, Bethesda, MD, USA). dot formation and nuclear translocation of TFEB. Interestingly, TFEB nuclear translocation occurs faster in FASN depleted NB4 cells compared to control cells (Fig. 6C), consistent with an increase in $\mathrm{LAMP}^{+}$dot formation (Fig. 6D-E). Furthermore, we treated cells with Acridine Orange to quantify the lysosomal integrity by flow cytometry. Acridine Orange is a cell-permeable fluorescent dye that, when excited at $488 \mathrm{~nm}$, emits light at $530 \mathrm{~nm}$ (GREEN) in its monomeric form but shifts its emission to $680 \mathrm{~nm}$ (RED) when accumulating and precipitating inside lysosomes. Therefore, we measured the RED/GREEN ratio of Acridine Orange stained cells by flow cytometry as previously described [61]. We found that ATRA treatment shifted the ratio towards the red channel (Supplementary Fig. 6C). Reducing FASN expression further accelerated the increase of the RED/GREEN ratio indicating enhanced lysosome biogenesis (Fig. 6G-H). These results suggest that FASN expression impairs TFEB translocation to the nucleus and therefore reduces lysosome biogenesis

We then evaluated the effect of FASN expression on the transcription of the following TFEB target genes: BECN1, GABARAP, STK4 and WDR45. All four TFEB targets showed increased expression upon ATRA treatment, in line with previous studies [14, 15, 62] (Fig. 6I). Knock down of FASN led to a further increase in the expression of $3 / 4$ TFEB targets analyzed (Fig. 6I). These results suggest that FASN retardation of TFEB translocation to the nucleus attenuates CLEAR network gene transcription.

Then, we tested whether we can obtain similar results by lowering FASN protein levels using EGCG. Using different 

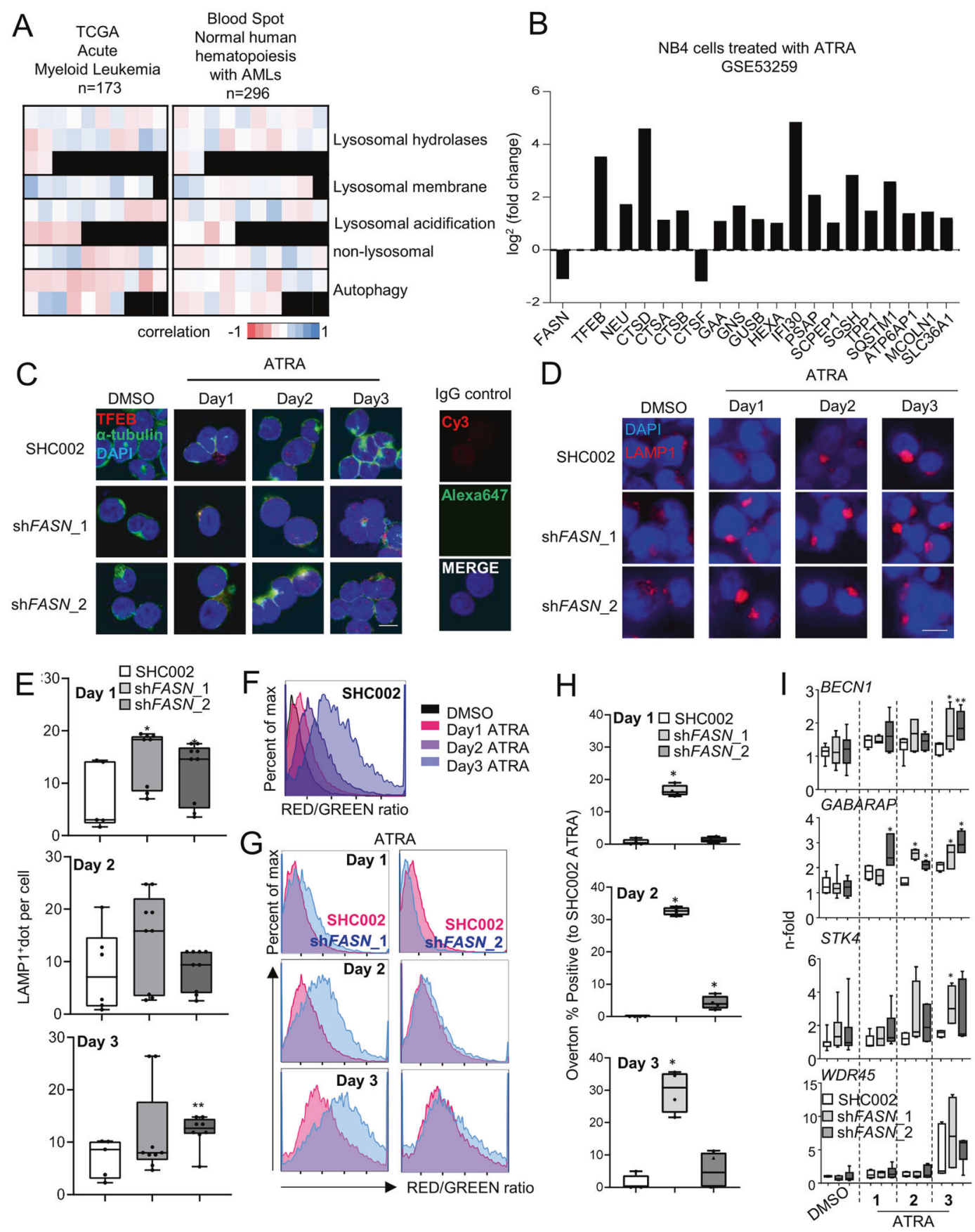

Fig. 6 FASN expression negatively associates with TFEB activity. A Heatmaps of the correlation between FASN and TFEB target genes extracted from the TCGA-AML cohort analyzed by the UCSD xena platform and from the blood spot data bank (Spearman, $p$ values in Supplementary Table 1 and 2). B mRNA sequencing data of NB4 cells treated with ATRA. Relative expression of FASN, TFEB and TFEB transcriptional targets involved in lysosomal function and biogenesis are shown. C-H NB4 control (SHC002) and FASN knockdown $\left(\operatorname{sh} F A S N \_1, \_2\right)$ cells were treated for 1-3 days with ATRA. C Immunofluorescence microscopy of endogenous TFEB (red) and $\alpha$ tubulin (green). IgG staining was used as negative control. Nuclei were stained with DAPI (blue). D Immunofluorescence microscopy of endogenous LAMP1 (red). Nuclei were stained with DAPI (blue).
Scale: $10 \mu \mathrm{m}(\mathbf{E})$ LAMP1 punctae quantification of cells shown in (D). Scale: $10 \mu \mathrm{m}(\mathbf{F}-\mathbf{H})$ Acridine Orange staining. F Histogram representation of the ratio between RED and GREEN of NB4 control (SHC002) cells treated as described in 6 C. G Representative histogram of NB4 control (SHC002) and FASN knockdown (shFASN_1, 2) cells treated as in $6 \mathrm{C}$. $\mathbf{H}$ Overton percentage positive quantification of the RED/GREEN ratio of NB4 control (SHC002) and FASN knockdown $\left(\operatorname{sh} F A S N \_1,2\right)$ cells treated with ATRA at indicated times. I Evaluation of BECN1, GABARAP, STK4 and WDR45 mRNA transcripts was done by qPCR. Values were normalized to the HMBS housekeeping gene. Results shown are from at least two biological duplicates. 

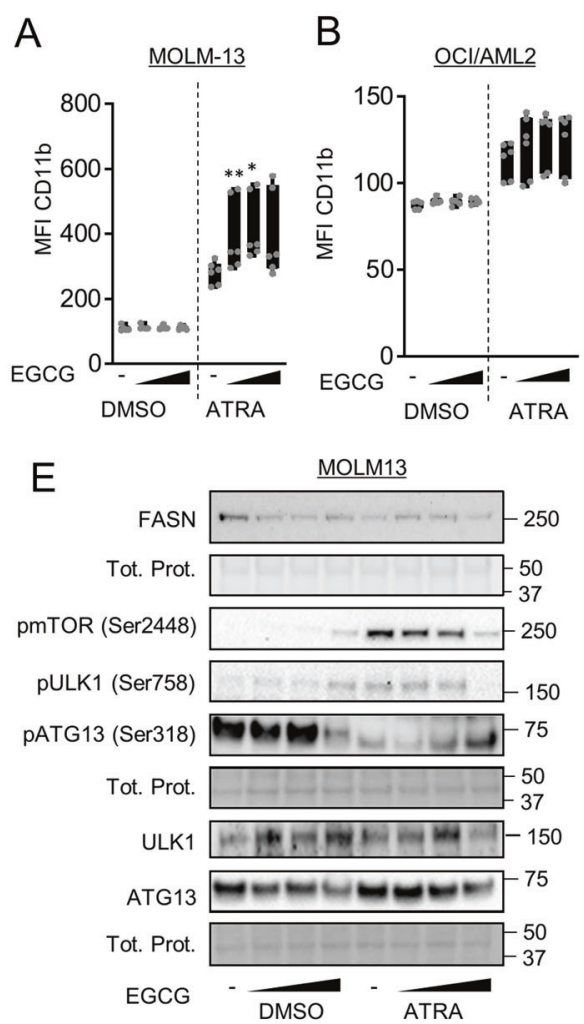

Fig. 7 Lowering FASN protein expression levels improves ATRA therapy in non-APL AML cells. A-F MOLM-13 (A, C, E), and OCI-AML2 (B, D, F) cells were treated with ATRA and different concentrations of EGCG $(5 \mu \mathrm{M}, 10 \mu \mathrm{M}$ and $15 \mu \mathrm{M})$ for 3 days $(n=3)$. A-B CD11b surface staining was analyzed by flow cytometry. Box blot represent the median fluorescence intensity (MFI) of CD11b

EGCG concentrations, we found a decrease in mTOR phosphorylation at Ser2448 (Supplementary Fig. 7A), an increase of TFEB translocation to the nucleus (Supplementary Fig. 7B), an increase of LAMP1 ${ }^{+}$vesicles (Supplementary Fig. 8A-B) and an increase of the RED/GREEN ratio in Acridine Orange stained cells similar to the results seen in FASN-depleted APL cells (Supplementary Fig. 8CE). In addition, we found an upregulation of 3/4 TFEB target genes in presence of EGCG in line with our FASN knockdown experiments (Supplementary Fig. 7C).

Together, these data suggest that high FASN expression results in lower autophagic activity and decreased lysosomal capacity due to increased mTOR activity causing TFEB inhibition.

\section{Lowering FASN expression improves ATRA therapy in non-APL AML cell lines by inhibiting the mTOR pathway}

Given the fact that APL cells treated with EGCG demonstrated improved response to ATRA therapy, we asked if EGCG can be beneficial to other AML subtypes that are refractory to ATRA treatment. We and others previously
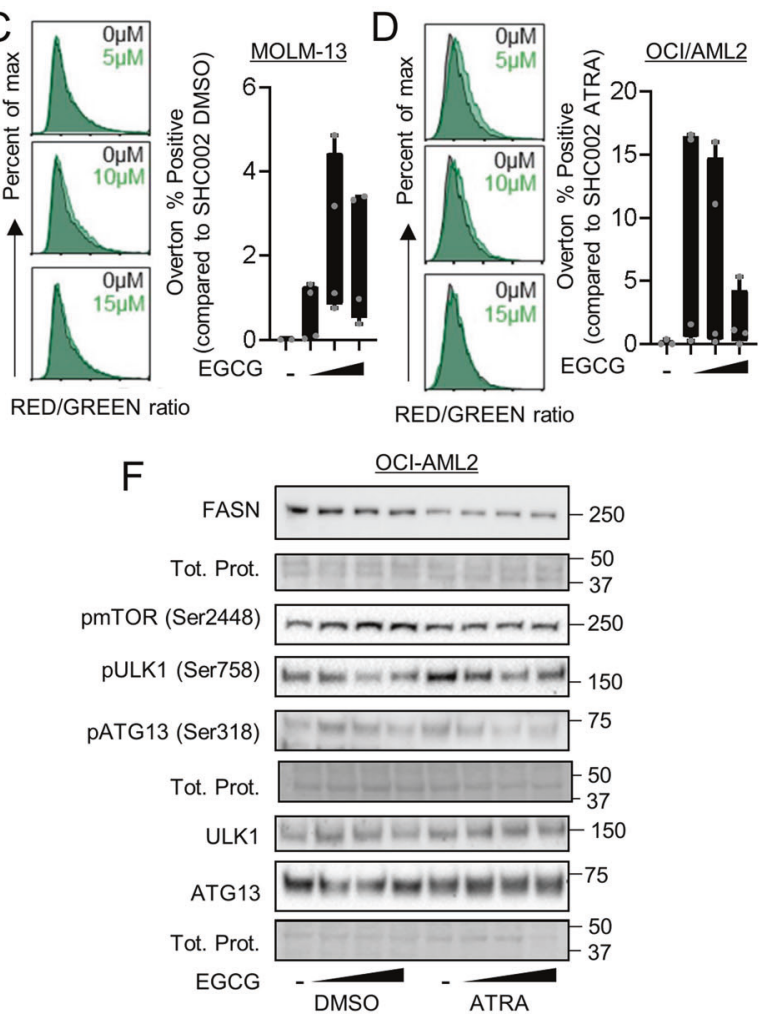

positive cells. C-D Acridine Orange staining. Analysis was performed as in Fig. 6E-G. E-F Total protein extracted from MOLM-13 and OCI-AML2 cells treated as in $7 \mathrm{~A} / \mathrm{B}$ were subjected to immunoblotting using anti-FASN, anti-pmTOR(Ser2448), anti- pULK1(Ser757), antiULK1, anti-pATG13(Ser318) and anti-ATG13 antibodies. Results shown are from at least two biological duplicates.

demonstrated a positive impact of co-treating HL60 AML cells, a non-APL AML cell line that responds to ATRA, with EGCG and ATRA [48, 63, 64]. Therefore, we tested if ATRA-refractory AML cell lines with different genetic backgrounds, namely MOLM-13 (FLT3-ITD ${ }^{+}$) and OCI/ AML2 (DNMT3A R635W mutation), would respond to ATRA in combination with EGCG. MOLM-13 showed significantly increased granulocytic differentiation upon the combination treatment as shown by $\mathrm{CD} 11 \mathrm{~b}$ surface expression while OCI/AML2 cells showed a clear but nonsignificant trend toward improved granulocytic differentiation (Fig. 7A-B). In addition, MOLM-13 and OCI/AML2showed an increase in the RED/GREEN ratio when stained with Acridine Orange (Fig. 7C-D). Furthermore, cotreatment with ATRA and EGCG led to a decrease in mTOR activity as seen by a decrease in mTOR (Ser2448) and ULK1 (Ser758) phosphorylation. In MOLM-13 cells, this was paralleled by an increase of ATG13 (Ser318) phosphorylation (Fig. 7E-F). We further confirmed these data by genetically inhibiting FASN in MOLM-13 (Fig. 8A) and OCI/AML2 (Fig. 8B) cells. Depleting FASN in both cell lines caused an increase of $\mathrm{CD} 11 \mathrm{~b}$ surface expression after 3 days of ATRA treatment (Fig. 8C-D), coupled with 


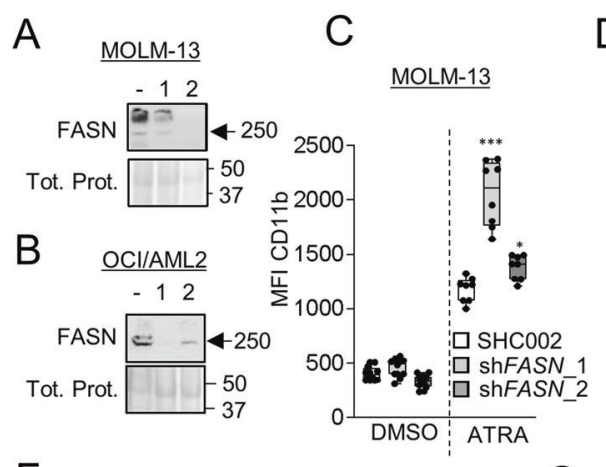

$\mathrm{F}$

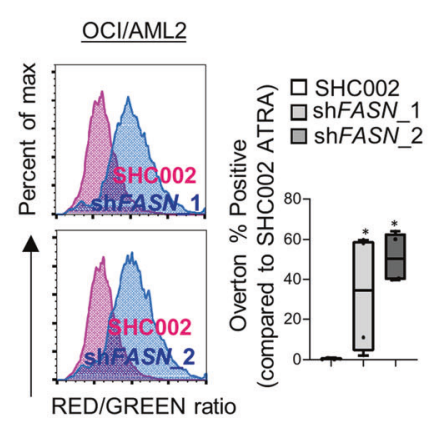

D

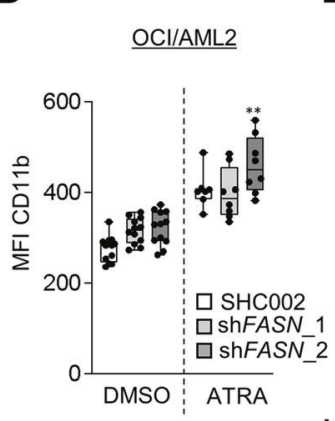

E

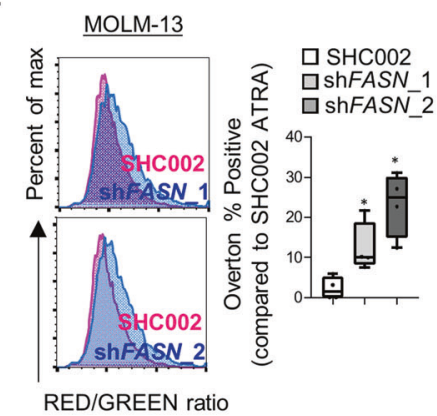

$\mathrm{H}$
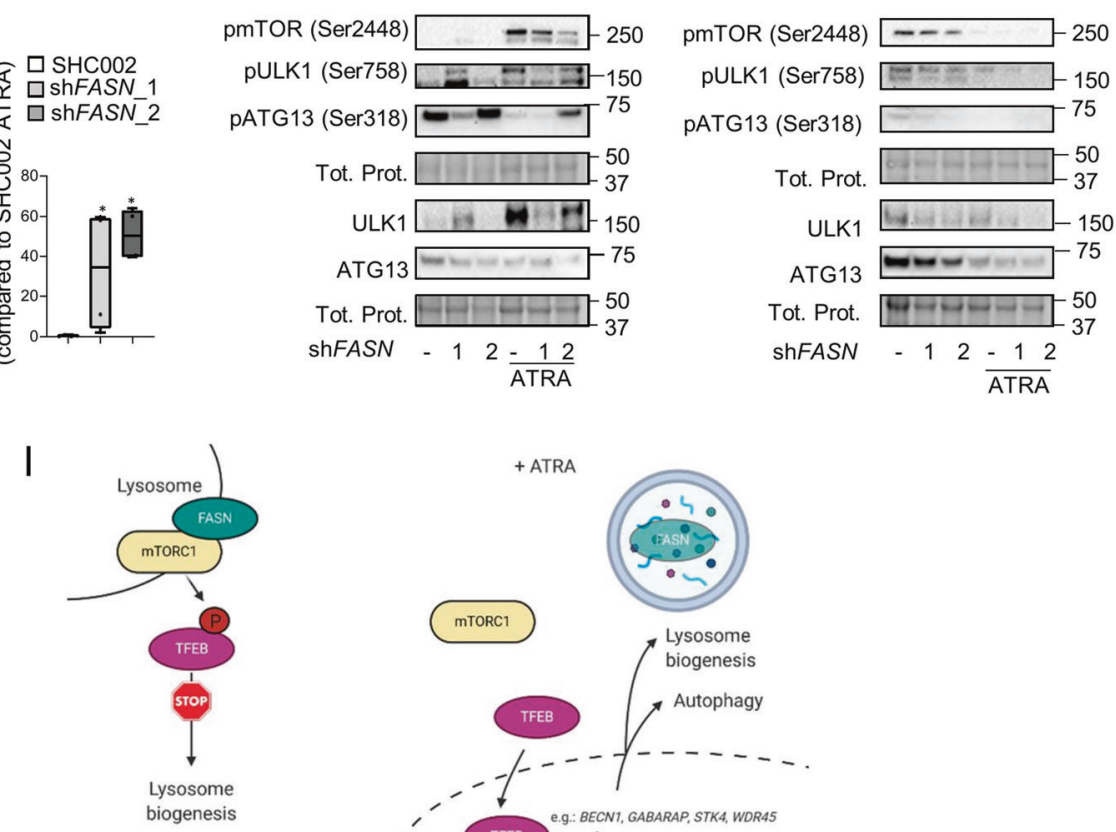

biogenesis

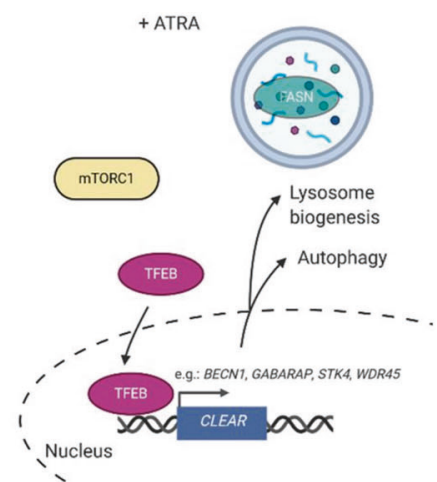

Fig. 8 MOLM-13 and OCI/AML2 were stably transduced with 2 independent shRNA targeting FASN $(n=3)$. A-B FASN knockdown efficiency was validated in MOLM-13 (A) and OCI/AML2 (B) by western blotting. C-H MOLM-13 and OCI/AML2 control and FASN knockdown cells were treated with ATRA for 3 days. C-D CD11b surface marker expression was analyzed as in (A-B). E-F Acridine Orange staining analysis was performed as in 7E-G. G-H Western blot analysis of total protein was extracted and

an increased RED/GREEN ratio when stained for Acridine Orange (Fig. 8E-F) and lower mTOR activity (Fig. 8G-H). Interestingly, we found more variation in lysosomal compartment changes between the experimental duplicates upon ATRA when cells were treated with EGCG (Fig. 7D, F) than in the knockdown cells (Fig. 8F, H), perhaps reflecting the lower specificity of EGCG.

Together, our data suggest that reducing FASN expression can increase lysosomal biogenesis and improve the differentiation of non-APL AML cells. We, therefore, propose that FASN is recruited to lysosomes in AML cells subjected to immunoblotting using anti-FASN, anti-pmTOR(Ser2448), anti- pULK1(Ser757), anti-ULK1, anti-pATG13(Ser318) and antiATG13 antibodies. Results shown are from at least two biological duplicates. I FASN localizes to lysosomes in AML with mTOR leading to the phosphorylation of TFEB and its sequestration in the cytoplasm. ATRA treatment resulted in FASN degradation by autophagy and thus TFEB translocation to the nucleus and activation of lysosomal biogenesis.

resulting in activation of mTOR and sequestration of TFEB in the cytoplasm (Fig. 8I). FASN degradation via autophagy resulted in activation of TFEB and its downstream targets (Fig. 8I).

\section{Discussion}

In this study, we aimed at further dissecting the function of FASN in AML cells and, in particular, its potential role in the differentiation of immature AML blasts. We showed 
that knocking down FASN accelerated ATRA-induced differentiation, while inhibition of its enzymatic function by pharmacological inhibitors such as C75 or Orlistat had no effect. Furthermore, we found that FASN expression activates mTOR resulting in sequestration of TFEB to the cytoplasm. Importantly, inhibiting $F A S N$ expression, in combination with ATRA treatment, improved differentiation therapy in non-APL AML cells.

Several studies demonstrated a tumor suppressor role of autophagy in AML cells. Autophagy can support degradation of leukemic oncogenes in AML such as FLT3-ITD and PML-RARA [10, 65, 66]. Furthermore, activation of mTORC1 is crucial for leukemia cell proliferation at least partially due to its inhibitory effect on autophagy [42, 67]. Accordingly, inhibition of autophagy leads to acceleration of MLL-ENL AML leukemia progression in vivo [42]. Our results indicate that increased FASN expression might be a key activator of mTORC1 in AML. Surprisingly, we found that reducing FASN protein levels, but not inhibition of catalytic function, promotes ATRA-induced differentiation. Recently, Bueno et al. demonstrated that FASN is key during the transformation from 2- to 3-dimensional growth of cancer cells. This transformation step does not depend on the FASN biosynthetic products palmitate, further hinting to at important non-catalytic functions of FASN in carcinogenesis [68]. Further studies on the interplay between FASN, mTOR and autophagy in AML transformation, progression and therapy resistance are warranted to improve our understanding of cell fate decisions and could potentially open new avenues to tackle this disease with improved differentiation therapies.

We further confirmed that EGCG positively impacts cellular differentiation in additional AML subtypes in vitro [48, 63, 64]. Searching for potential mediators of the positive effects of EGCG observed during ATRA-induced differentiation, we previously found that EGCG induces expression of the $\mathrm{Ca}^{2+}$ /calmodulin-regulated serine/threonine kinase DAPK2. DAPK2 plays a major role in granulocytic differentiation and decreased DAPK2 expression in APL cells can be restored by ATRA and EGCG treatment $[13,38,48]$. DAPK2 also negatively regulates mTOR via phosphorylation of raptor at Ser721 as shown in HeLa cells [69]. Therefore, a potential impact of FASN on DAPK2 activity in a leukemic context warrants further investigation.

Interestingly, treating APL cells with ATRA had a negative effect on FASN protein levels (Fig. 1C), and we demonstrated that ATRA-induced autophagy contributes to FASN protein degradation. Furthermore, FASN reduction led to increased lysosomal biogenesis suggesting a negative feedback loop between autophagy and FASN. It is reasonable to hypothesize that the more AML cells differentiate the more they become competent to degrade long-lived proteins including FASN. In addition, inhibiting mTOR using Rapamycin or Everolimus accelerates differentiation of APL cells $[10,12]$. While PI3K/AKT/mTOR pathways are activated in about $80 \%$ of AML cases, mTOR inhibitors had only modest effects in AML therapy [70, 71]. Furthermore, despite its role in leukemia cells, mTOR activity is crucial for hematopoietic stem cell (HSC) proliferation and self-renewal potential [72]. Therefore, targeting FASN with low expression in healthy progenitor cells would allow activation of autophagy in AML cells sparing healthy HSC cells in the bone marrow. In our hands, EGCG treatment only demonstrated partial effects regarding improved differentiation when compared to knocking down FASN in non-APL AML cells. Therefore, a more specific FASN expression inhibitor is needed to improve differentiation therapy in non-APL AML patients.

Indeed, it would be of interest to study the transcriptional regulation of FASN to influence its expression in autophagy-deficient cells. Consistently, there are several studies showing that FASN transcription is positively affected by retinoic acids [73, 74]. However, transcription induction is not mediated by a classic retinoic acidresponsive element but rather by the indirect influence of retinoic acid via cis-regulatory elements. Since this involves different cofactors it is tempting to speculate that transcriptional activation might switch to repression depending on the cellular context including specific retinoid-binding proteins and cofactors. We previously found that members of the KLF transcription factor family are often deregulated in primary AML patient samples. Among the different KLF family members downregulated in AML, particularly KLF5 turned out to be essential for granulocytic differentiation $[75,76]$. KLF5 forms a transcriptionally active complex with RAR/RXR heterodimers [77, 78]. Interestingly, ectopic expression of KLF5 in U937 non-APL AML cell line was sufficient to significantly increase ATRA-induced differentiation [79]. We hypothesize that KLF5 negatively regulates FASN transcription in AML cells via the RAR/ RXR complex.

In summary, our data suggest that inducing FASN protein degradation is likely to be beneficial for differentiation therapy of non-APL AML cells as this will impede mTOR and promote TFEB transcriptional activity and autophagy. Furthermore, high FASN expression in AML is partially based on attenuated autophagy activity in this disease.

Acknowledgements Deborah Shan-Krauer is gratefully acknowledged for excellent technical support. We thank Dr. MS Soengas for providing a mCherry-LC3B lentiviral vector. We thank Dr. Stefan Freigang for his help with the revision experiments. All schematic representations were created with Biorender.com.

Author contributions $\mathrm{MH}, \mathrm{KS}, \mathrm{KS}, \mathrm{SM}$, and VR performed the experimental research. MH, KS, SMCK and MPT drafted the article. 
SMCK, and AVP provided essential reagents and data. MH designed the project. MPT gave final approval of the submitted paper.

Funding This study was supported by grants from Swiss Cancer Research (KFS-3409-02-2014 to MPT, MD-PhD 03/17 Scholarship to KS), the Swiss National Science Foundation (31003A_173219 to MPT), the Berne University Research Foundation (45/2018, to MPT), the University of Bern initiator grant, the Bernese Cancer League, "Stiftung für klinisch-experimentelle Tumorforschung", and the Werner and Hedy Berger-Janser Foundation for Cancer Research (to $\mathrm{MH})$. SMCK is supported by Breakthrough Cancer Research. Open Access funding provided by Universität Bern.

\section{Compliance with ethical standards}

Conflict of interest The authors declare no competing interests.

Ethical approval Protocols and use of 67 human samples acquired in Bern were approved by the Cantonal Ethical Committee at the Inselspital.

Publisher's note Springer Nature remains neutral with regard to jurisdictional claims in published maps and institutional affiliations.

Open Access This article is licensed under a Creative Commons Attribution 4.0 International License, which permits use, sharing, adaptation, distribution and reproduction in any medium or format, as long as you give appropriate credit to the original author(s) and the source, provide a link to the Creative Commons license, and indicate if changes were made. The images or other third party material in this article are included in the article's Creative Commons license, unless indicated otherwise in a credit line to the material. If material is not included in the article's Creative Commons license and your intended use is not permitted by statutory regulation or exceeds the permitted use, you will need to obtain permission directly from the copyright holder. To view a copy of this license, visit http://creativecommons. org/licenses/by/4.0/

\section{References}

1. Wang Z-Y, Chen Z. Acute promyelocytic leukemia: from highly fatal to highly curable. Blood. 2008;111:2505-15.

2. Germain P, Chambon P, Eichele G, Evans RM, Lazar MA, Leid $\mathrm{M}$, et al. International Union of Pharmacology. LX. Retinoic acid receptors. Pharm Rev. 2006;58:712-25.

3. Su M, Alonso S, Jones JW, Yu J, Kane MA, Jones RJ, et al. AllTrans Retinoic Acid Activity in Acute Myeloid Leukemia: role of Cytochrome P450 Enzyme Expression by the Microenvironment. PLOS ONE. 2015;10:e0127790.

4. Marchwicka A, Cebrat M, Sampath P, Śnieżewski Ł, Marcinkowska E. Perspectives of Differentiation Therapies of Acute Myeloid Leukemia: the Search for the Molecular Basis of Patients' Variable Responses to 1,25-Dihydroxyvitamin D and Vitamin D Analogs. Front Oncol. 2014; 4. https://doi.org/10. 3389/fonc.2014.00125.

5. Schenk T, Chen WC, Göllner S, Howell L, Jin L, Hebestreit K, et al. Inhibition of the LSD1 (KDM1A) demethylase reactivates the all-trans-retinoic acid differentiation pathway in acute myeloid leukemia. Nat Med. 2012;18:605-611.

6. Rice AM, Holtz KM, Karp J, Rollins S, Sartorelli AC. Analysis of the relationship between Scl transcription factor complex protein expression patterns and the effects of $\mathrm{LiCl}$ on ATRA-induced differentiation in blast cells from patients with acute myeloid leukemia. Leuk Res. 2004;28:1227-37.

7. Bullinger L, Schlenk RF, Götz M, Botzenhardt U, Hofmann S, Russ AC, et al. PRAME-induced inhibition of retinoic acid receptor signaling-mediated differentiation-a possible target for ATRA response in AML without $\mathrm{t}(15 ; 17)$. Clin Cancer Res J Am Assoc Cancer Res. 2013;19:2562-71.

8. Petrie K, Zelent A, Waxman S. Differentiation therapy of acute myeloid leukemia: past, present and future. Curr Opin Hematol. 2009;16:84-91.

9. Altucci L, Gronemeyer $\mathrm{H}$. The promise of retinoids to fight against cancer. Nat Rev Cancer. 2001;1:181-93.

10. Isakson $\mathrm{P}, \mathrm{Bj} \emptyset \mathrm{rås} \mathrm{M}, \mathrm{B} \emptyset \mathrm{e} \mathrm{SO}$, Simonsen A. Autophagy contributes to therapy-induced degradation of the PML/RARA oncoprotein. Blood. 2010;116:2324-31.

11. Wang Z, Cao L, Kang R, Yang M, Liu L, Zhao Y, et al. Autophagy regulates myeloid cell differentiation by p62/ SQSTM1-mediated degradation of PML-RAR $\alpha$ oncoprotein. Autophagy. 2011;7:401-11.

12. Jin J, Britschgi A, Schläfli AM, Humbert M, Shan-Krauer D, Batliner J, et al. Low Autophagy (ATG) Gene Expression Is Associated with an Immature AML Blast Cell Phenotype and Can Be Restored during AML Differentiation Therapy. Oxid Med Cell Longev. 2018;2018:1482795.

13. Humbert M, Federzoni EA, Tschan MP. Distinct TP73-DAPK2ATG5 pathway involvement in ATO-mediated cell death versus ATRA-mediated autophagy responses in APL. J Leukoc Biol. 2017;102:1357-70.

14. Brigger D, Proikas-Cezanne T, Tschan MP. WIPI-dependent autophagy during neutrophil differentiation of NB4 acute promyelocytic leukemia cells. Cell Death Dis. 2014;5:e1315.

15. Orfali N, O’Donovan TR, Cahill MR, Benjamin D, Nanus DM, McKenna SL et al. All-trans retinoic acid (ATRA) induced TFEB expression is required for myeloid differentiation in acute promyelocytic leukemia (APL). Eur J Haematol. 2019. https://doi. org/10.1111/ejh.13367.

16. Feng Y, He D, Yao Z, Klionsky DJ. The machinery of macroautophagy. Cell Res. 2014;24:24-41.

17. Asturias FJ, Chadick JZ, Cheung IK, Stark H, Witkowski A, Joshi $\mathrm{AK}$, et al. Structure and molecular organization of mammalian fatty acid synthase. Nat Struct Mol Biol. 2005;12:225-32.

18. Maier T, Jenni S, Ban N. Architecture of mammalian fatty acid synthase at 4.5 \AA resolution. Science. 2006;311:1258-62.

19. Pizer ES, Lax SF, Kuhajda FP, Pasternack GR, Kurman RJ. Fatty acid synthase expression in endometrial carcinoma. Cancer. 1998;83:528-37.

20. Visca P, Sebastiani V, Botti C, Diodoro MG, Lasagni RP, Romagnoli F, et al. Fatty acid synthase (FAS) is a marker of increased risk of recurrence in lung carcinoma. Anticancer Res. 2004;24:4169-73.

21. Bandyopadhyay S, Pai SK, Watabe M, Gross SC, Hirota S, Hosobe S, et al. FAS expression inversely correlates with PTEN level in prostate cancer and a PI 3-kinase inhibitor synergizes with FAS siRNA to induce apoptosis. Oncogene. 2005;24:5389-95.

22. Alo PL, Visca P, Marci A, Mangoni A, Botti C, Di Tondo U. Expression of fatty acid synthase (FAS) as a predictor of recurrence in stage I breast carcinoma patients. Cancer. 1996;77:474-82.

23. Shurbaji MS, Kalbfleisch JH, Thurmond TS. Immunohistochemical detection of a fatty acid synthase (OA-519) as a predictor of progression of prostate cancer. Hum Pathol. 1996;27:917-21.

24. Rashid A, Pizer ES, Moga M, Milgraum LZ, Zahurak M, Pasternack GR, et al. Elevated expression of fatty acid synthase and fatty acid synthetic activity in colorectal neoplasia. Am J Pathol. 1997;150:201-8. 
25. Diaz-Blanco E, Bruns I, Neumann F, Fischer JC, Graef T, Rosskopf M, et al. Molecular signature of CD34(+) hematopoietic stem and progenitor cells of patients with CML in chronic phase. Leukemia. 2007;21:494-504.

26. Weiss L, Hoffmann GE, Schreiber R, Andres H, Fuchs E, Körber E, et al. Fatty-acid biosynthesis in man, a pathway of minor importance. Purification, optimal assay conditions, and organ distribution of fatty-acid synthase. Biol Chem Hoppe Seyler. 1986;367:905-12.

27. Pizer ES, Kurman RJ, Pasternack GR, Kuhajda FP. Expression of fatty acid synthase is closely linked to proliferation and stromal decidualization in cycling endometrium. Int J Gynecol Pathol J Int Soc Gynecol Pathol. 1997;16:45-51.

28. Maningat PD, Sen P, Rijnkels M, Sunehag AL, Hadsell DL, Bray $\mathrm{M}$, et al. Gene expression in the human mammary epithelium during lactation: the milk fat globule transcriptome. Physiol Genom. 2009;37:12-22.

29. Park J, Lee SE, Hur J, Hong EB, Choi J-I, Yang J-M, et al. MCSF from Cancer Cells Induces Fatty Acid Synthase and PPAR $\beta /$ $\delta$ Activation in Tumor Myeloid Cells, Leading to Tumor Progression. Cell Rep. 2015;10:1614-25.

30. Peters JM, Gonzalez FJ. Sorting out the functional role(s) of peroxisome proliferator-activated receptor- $\beta / \delta(\operatorname{PPAR} \beta / \delta)$ in cell proliferation and cancer. Biochim Biophys Acta BBA - Rev Cancer. 2009;1796:230-41.

31. Zuo X, Peng Z, Moussalli MJ, Morris JS, Broaddus RR, Fischer SM, et al. Targeted Genetic Disruption of Peroxisome Proliferator-Activated Receptor- $\delta$ and Colonic Tumorigenesis. JNCI J Natl Cancer Inst. 2009;101:762-7.

32. Jung-Kyu Han, Hyun-Sook Lee, Han-Mo Yang, Jin Hur, Soo-In Jun, Ju-Young Kim, et al. Peroxisome Proliferator-Activated Receptor- $\delta$ Agonist Enhances Vasculogenesis by Regulating Endothelial Progenitor Cells Through Genomic and Nongenomic Activations of the Phosphatidylinositol 3-Kinase/Akt Pathway. Circulation. 2008;118:1021-33.

33. Kang K, Reilly SM, Karabacak V, Gangl MR, Fitzgerald K, Hatano B, et al. Adipocyte-Derived Th2 Cytokines and Myeloid PPAR $\delta$ Regulate Macrophage Polarization and Insulin Sensitivity. Cell Metab. 2008;7:485-95.

34. Lee C-H, Chawla A, Urbiztondo N, Liao D, Boisvert WA, Evans RM. Transcriptional Repression of Atherogenic Inflammation: Modulation by PPARס. Science. 2003;302:453-7.

35. Odegaard JI, Ricardo-Gonzalez RR, Red Eagle A, Vats D, Morel $\mathrm{CR}$, Goforth $\mathrm{MH}$, et al. Alternative M2 Activation of Kupffer Cells by PPARS Ameliorates Obesity-Induced Insulin Resistance. Cell Metab. 2008;7:496-507.

36. Yeh CW, Chen WJ, Chiang CT, Lin-Shiau SY, Lin JK. Suppression of fatty acid synthase in MCF-7 breast cancer cells by tea and tea polyphenols: a possible mechanism for their hypolipidemic effects. Pharmacogenomics J. 2003;3:267.

37. Tschan MP, Fischer KM, Fung VS, Pirnia F, Borner MM, Fey $\mathrm{MF}$, et al. Alternative splicing of the human cyclin D-binding Myb-like protein (hDMP1) yields a truncated protein isoform that alters macrophage differentiation patterns. J Biol Chem. 2003;278:42750-60.

38. Rizzi M, Tschan MP, Britschgi C, Britschgi A, Hügli B, Grob TJ, et al. The death-associated protein kinase 2 is up-regulated during normal myeloid differentiation and enhances neutrophil maturation in myeloid leukemic cells. J Leukoc Biol. 2007;81:1599-608.

39. Tschan MP, Shan D, Laedrach J, Eyholzer M, Leibundgut EO, Baerlocher GM, et al. NDRG1/2 expression is inhibited in primary acute myeloid leukemia. Leuk Res. 2010;34:393-8.

40. Gubern A, Barceló-Torns M, Casas J, Barneda D, Masgrau R, Picatoste F, et al. Lipid Droplet Biogenesis Induced by Stress Involves Triacylglycerol Synthesis That Depends on Group VIA Phospholipase A2. J Biol Chem. 2009;284:5697-708.
41. Bagger FO, Sasivarevic D, Sohi SH, Laursen LG, Pundhir S, Sønderby CK, et al. BloodSpot: a database of gene expression profiles and transcriptional programs for healthy and malignant haematopoiesis. Nucleic Acids Res. 2016;44:D917-24.

42. Watson AS, Riffelmacher T, Stranks A, Williams O, De Boer J, Cain $\mathrm{K}$ et al. Autophagy limits proliferation and glycolytic metabolism in acute myeloid leukemia. Cell Death Discov. 2015; 1. https://doi.org/10.1038/cddiscovery.2015.8.

43. Volpe JJ, Vagelos PR. Mechanisms and regulation of biosynthesis of saturated fatty acids. Physiol Rev. 1976;56:339-417.

44. Dengjel J, Høyer-Hansen M, Nielsen MO, Eisenberg T, Harder LM, Schandorff $\mathrm{S}$ et al. Identification of Autophagosomeassociated Proteins and Regulators by Quantitative Proteomic Analysis and Genetic Screens. Mol Cell Proteomics. MCP 2012; 11. https://doi.org/10.1074/mcp.M111.014035.

45. Suzuki K, Nakamura S, Morimoto M, Fujii K, Noda NN, Inagaki F, et al. Proteomic Profiling of Autophagosome Cargo in Saccharomyces cerevisiae. PLOS ONE. 2014;9:e91651.

46. Yamamoto A, Tagawa Y, Yoshimori T, Moriyama Y, Masaki R, Tashiro Y. Bafilomycin A1 prevents maturation of autophagic vacuoles by inhibiting fusion between autophagosomes and lysosomes in rat hepatoma cell line, H-4-II-E cells. Cell Struct Funct. 1998;23:33-42.

47. Poole B, Ohkuma S. Effect of weak bases on the intralysosomal pH in mouse peritoneal macrophages. J Cell Biol. 1981;90:665-9.

48. Britschgi A, Simon H-U, Tobler A, Fey MF, Tschan MP. Epigallocatechin-3-gallate induces cell death in acute myeloid leukaemia cells and supports all-trans retinoic acid-induced neutrophil differentiation via death-associated protein kinase 2 . Br J Haematol. 2010;149:55-64.

49. Gump JM, Thorburn A. Sorting cells for basal and induced autophagic flux by quantitative ratiometric flow cytometry. Autophagy. 2014;10:1327-34.

50. Klionsky DJ, Abdelmohsen K, Abe A, Abedin MJ, Abeliovich H, Acevedo Arozena A, et al. Guidelines for the use and interpretation of assays for monitoring autophagy (3rd edition). Autophagy. 2016;12:1-222.

51. Hu J, Che L, Li L, Pilo MG, Cigliano A, Ribback S, et al. Coactivation of AKT and c-Met triggers rapid hepatocellular carcinoma development via the mTORC1/FASN pathway in mice. Sci Rep. 2016;6:20484.

52. Calvisi DF, Wang C, Ho C, Ladu S, Lee SA, Mattu S, et al. Increased lipogenesis, induced by AKT-mTORC1-RPS6 signaling, promotes development of human hepatocellular carcinoma. Gastroenterology. 2011;140:1071-83.

53. Kim J, Kundu M, Viollet B, Guan K-LAMPK. and mTOR regulate autophagy through direct phosphorylation of Ulk1. Nat Cell Biol. 2011;13:132-41.

54. Joo JH, Dorsey FC, Joshi A, Hennessy-Walters KM, Rose KL, McCastlain K, et al. Hsp90-Cdc37 Chaperone Complex Regulates Ulk1- and Atg13-Mediated Mitophagy. Mol Cell. 2011;43:572-85.

55. Petherick KJ, Conway OJL, Mpamhanga C, Osborne SA, Kamal A, Saxty B, et al. Pharmacological Inhibition of ULK1 Kinase Blocks Mammalian Target of Rapamycin (mTOR)-dependent Autophagy. J Biol Chem. 2015;290:11376-83.

56. Vega-Rubin-de-Celis S, Peña-Llopis S, Konda M, Brugarolas J. Multistep regulation of TFEB by MTORC1. Autophagy. 2017;13:464-72.

57. Peña-Llopis S, Vega-Rubin-de-Celis S, Schwartz JC, Wolff NC, Tran TAT, Zou L, et al. Regulation of TFEB and V-ATPases by mTORC1. EMBO J. 2011;30:3242-58.

58. Roczniak-Ferguson A, Petit CS, Froehlich F, Qian S, Ky J, Angarola B, et al. The transcription factor TFEB links mTORC1 signaling to transcriptional control of lysosome homeostasis. Sci Signal. 2012;5:ra42. 
59. Napolitano G, Esposito A, Choi H, Matarese M, Benedetti V, Malta CD, et al. mTOR-dependent phosphorylation controls TFEB nuclear export. Nat Commun. 2018;9:3312.

60. Goldman M, Craft B, Hastie M, Repečka K, McDade F, Kamath A, et al. The UCSC Xena platform for public and private cancer genomics data visualization and interpretation. bioRxiv. 2019;6:326470.

61. Thomé MP, Filippi-Chiela EC, Villodre ES, Migliavaca CB, Onzi GR, Felipe KB, et al. Ratiometric analysis of Acridine Orange staining in the study of acidic organelles and autophagy. J Cell Sci. 2016;129:4622-32.

62. Brigger D, Torbett BE, Chen J, Fey MF, Tschan MP. Inhibition of GATE-16 attenuates ATRA-induced neutrophil differentiation of APL cells and interferes with autophagosome formation. Biochem Biophys Res Commun. 2013;438:283-8.

63. Moradzadeh M, Roustazadeh A, Tabarraei A, Erfanian S, Sahebkar A. Epigallocatechin-3-gallate enhances differentiation of acute promyelocytic leukemia cells via inhibition of PML-RAR $\alpha$ and HDAC1. Phytother Res PTR. 2018;32:471-9.

64. Lung HL, Ip WK, Wong CK, Mak NK, Chen ZY, Leung KN. Antiproliferative and differentiation-inducing activities of the green tea catechin epigallocatechin-3-gallate (EGCG) on the human eosinophilic leukemia EoL-1 cell line. Life Sci. 2002;72:257-68.

65. Larrue C, Saland E, Boutzen H, Vergez F, David M, Joffre C, et al. Proteasome inhibitors induce FLT3-ITD degradation through autophagy in AML cells. Blood. 2016;127:882-92.

66. Rudat S, Pfaus A, Cheng YY, Holtmann J, Ellegast JM, Bühler C, et al. RET-mediated autophagy suppression as targetable codependence in acute myeloid leukemia. Leukemia. 2018;32:2189-202.

67. Hoshii T, Tadokoro $\mathrm{Y}$, Naka $\mathrm{K}$, Ooshio $\mathrm{T}$, Muraguchi $\mathrm{T}$, Sugiyama N, et al. mTORC1 is essential for leukemia propagation but not stem cell self-renewal. J Clin Investig. 2012;122:2114-29.

68. Bueno MJ, Jimenez-Renard V, Samino S, Capellades J, Junza A, López-Rodríguez ML, et al. Essentiality of fatty acid synthase in the $2 \mathrm{D}$ to anchorage-independent growth transition in transforming cells. Nat Commun. 2019;10:5011.
69. Ber Y, Shiloh R, Gilad Y, Degani N, Bialik S, Kimchi A. DAPK2 is a novel regulator of mTORC1 activity and autophagy. Cell Death Differ. 2015;22:465-75.

70. Mirabilii S, Ricciardi MR, Piedimonte M, Gianfelici V, Bianchi MP, Tafuri A Biological Aspects of mTOR in Leukemia. Int J Mol Sci. 2018; 19. https://doi.org/10.3390/ijms19082396.

71. Tabe Y, Tafuri A, Sekihara K, Yang H, Konopleva M. Inhibition of mTOR kinase as a therapeutic target for acute myeloid leukemia. Expert Opin Ther Targets. 2017;21:705-14.

72. Ghosh J, Kapur R. Regulation of Hematopoietic Stem Cell SelfRenewal and Leukemia Maintenance by the PI3K-mTORC1 Pathway. Curr Stem. Cell Rep. 2016;2:368-78.

73. Roder K, Wolf SS, Schweizer M. Regulation of the fatty acid synthase promoter by retinoic acid. Biochem Soc Trans. 1996;24:233S.

74. Roder K, Schweizer M. Retinoic acid-mediated transcription and maturation of SREBP-1c regulates fatty acid synthase via ciselements responsible for nutritional regulation. Biochem Soc Trans. 2007;35:1211-4.

75. Humbert M, Halter V, Shan D, Laedrach J, Leibundgut EO, Baerlocher GM, et al. Deregulated expression of Kruppel-like factors in acute myeloid leukemia. Leuk Res. 2011;35:909-13.

76. Diakiw SM, Kok CH, Lewis LB, Brown ID, D'Andrea AL. RJ. The granulocyte-associated transcription factor Krüppel-like factor 5 is silenced by hypermethylation in acute myeloid leukemia. Leuk Res. 2012;36:110-6.

77. Lv X-R, Zheng B, Li S-Y, Han A-L, Wang C, Shi J-H, et al. Synthetic retinoid Am80 up-regulates apelin expression by promoting interaction of RAR $\alpha$ with KLF5 and Sp1 in vascular smooth muscle cells. Biochem J. 2013;456:35-46.

78. Kada N, Suzuki T, Aizawa K, Munemasa Y, Matsumura T, Sawaki D, et al. Acyclic retinoid inhibits functional interaction of transcription factors Krüppel-like factor 5 and retinoic acid receptor-alpha. FEBS Lett. 2008;582:1755-60.

79. Shahrin NH, Diakiw S, Dent LA, Brown AL, D'Andrea RJ. Conditional knockout mice demonstrate function of Klf5 as a myeloid transcription factor. Blood. 2016;128:55-59. 